Article

\title{
Kinetic, Isotherm, and Thermodynamic Studies for Ag(I) Adsorption Using Carboxymethyl Functionalized Poly(glycidyl methacrylate)
}

\author{
Jiling Zhao ${ }^{1,2,3,4}$, Shixing Wang ${ }^{1,2,3,4, *}$, Libo Zhang ${ }^{1,2,3,4, * \mathbb{D}}$, Chen Wang ${ }^{2,3,4}$ \\ and Bing Zhang $2,3,4$ \\ 1 State Key Laboratory of Complex Nonferrous Metal Resources Clean Utilization, Kunming University of \\ Science and Technology, Kunming 650093, China; 15687884157@163.com \\ 2 National Local Joint Laboratory of Engineering Application of Microwave Energy and Equipment \\ Technology, Kunming 650093, China; wc932608335@163.com (C.W.); 15198750002@163.com (B.Z.) \\ 3 Faculty of Metallurgical and Energy Engineering, Kunming University of Science and Technology, \\ Kunming 650093, China \\ 4 Key Laboratory of Unconventional Metallurgical Ministry of Education, Kunming 650093, China \\ * Correspondence: wsxkm@kmust.edu.cn (S.W.) \& zhanglibopaper@126.com (L.Z.); \\ Tel.: +86-871-6513-8997 (S.W.)
}

Received: 5 September 2018; Accepted: 29 September 2018; Published: 1 October 2018

\begin{abstract}
Industrial wastewater contains large amounts of silver ions. Here, a new adsorbent was synthesized by functionalizing poly(glycidyl methacrylate) with carboxymethyl groups. The adsorbent was used to recover $\mathrm{Ag}(\mathrm{I})$ in wastewater. Fourier transform infrared spectroscopy, zeta potential, scanning electron microscopy, and X-ray photoelectron spectroscopy were used to characterize the adsorbent. The experimental parameters affecting the adsorption are solution $\mathrm{pH}$, contact time, and initial silver ion concentration. The optimum $\mathrm{pH}$ for adsorption of $\mathrm{Ag}(\mathrm{I})$ is $\mathrm{pH}$ 4. The maximum adsorption capacity at $\mathrm{pH} 4$ is $157.05 \mathrm{mg} / \mathrm{g}$, and the adsorption reaches equilibrium at $300 \mathrm{~min}$. The kinetics and isotherms of the adsorption process were described by pseudo second-order, Langmuir and D-R models, respectively. The adsorption process was a single layer chemical adsorption, exothermic, feasible, and spontaneous. The adsorption mechanism is electrostatic or chelation. The adsorbent selectively absorbed $\mathrm{Ag}(\mathrm{I})$ from coexisting ions $\left(\mathrm{Cu}^{2+}, \mathrm{Ni}^{2+}\right.$, $\mathrm{Co}^{2+}, \mathrm{Zn}^{2+}$ ). Finally, the removal rate of silver ions decreased from $79.29 \%$ to $65.01 \%$ after four repetitive experiments, which proved that the adsorbent had good reusability. The adsorbent has great potential benefit in removing $\mathrm{Ag}(\mathrm{I})$.
\end{abstract}

Keywords: polymer; Ag (I), removal; mechanism; adsorption

\section{Introduction}

In many parts of the world, clean and safe water is becoming scarcer, mainly due to pollution [1,2]. Wastewater discharged in many industries, such as metallurgy, mineral processing, tanning, chemical manufacturing, and battery manufacturing, contains one or more toxic metal ions [3]. Among them, silver is one of the most toxic metals due to its instability [4]. If the wastewater is not treated in time, $\mathrm{Ag}(\mathrm{I})$ will circulate with the water, immerse into the groundwater or be exposed to the air, and may result in causing various diseases. [5-8]. On the other hand, due to its excellent properties, silver is widely used in medical products, photography, electronics, and other important fields $[9,10]$. Therefore, the recovery of silver from wastewater has high economic and environmental significance.

The developed treatment technologies for silver from wastewater include ion exchange, solvent extraction, precipitation, electrolysis, and adsorption [11-14]. Among these technologies, adsorption is 
considered a promising method for removing $\mathrm{Ag}(\mathrm{I})$ because of its high absorption capacity, reusability, low cost, and environmental friendliness [15-17]. Currently, various adsorbents have been used such as silica gel, activated carbon, fiber, biomaterials, and polymeric materials [18-21]. In contrast, polymer resins with various functional groups have high selectivity, easy desorption, and good structural diversity [20]. Recently, poly(glycidyl methacrylate) (PGMA)-based chelating resins have received a lot of attention and were successfully applied to the adsorption of heavy metals, noble metals, and dyes in wastewater [22-24] because PGMA-based chelating resins have acid and alkaline resistance, good mechanical strength, high tensile strength, wear resistance, and low cost [25]. The most outstanding characteristics of PGMA is that it contains highly reactive epoxy groups, has a porous structure, and is easily functionalized with various group by a single chemical reaction [26,27]. Therefore, PGMA-based chelating adsorbents have good industrial application prospects in the removal of metal ions from wastewater.

In recent years, PGMA has been functionalized by coordination groups containing donor atoms such as $\mathrm{O}, \mathrm{N}, \mathrm{S}$ and $\mathrm{P}$ for removal of different metal ions. Liu et al. removed $\mathrm{Cu}$ (II) by poly(glycidyl methacrylate) (PGMA) modified with diethylenetriamine [28]. Krajnc et al. functionalized PGMA with penta-erythritol tetrakis(3-mercaptopropionate), 1,9-nonanedithiol, and 2-aminobenzenethiol for removal of silver, lead, and cadmium from water [29]. Polyethylenimine-grafted poly(glycidyl methacrylate) (PGMA-PEI) microspheres adsorbed selectively $\mathrm{Cr}(\mathrm{VI})$ from coexisting ions of $\mathrm{K}^{+}, \mathrm{Na}^{+}$, $\mathrm{Ca}^{2+}, \mathrm{Cu}^{2+}, \mathrm{Cl}^{-}, \mathrm{NO}_{3}{ }^{-}, \mathrm{H}_{2} \mathrm{PO}_{4}{ }^{-}$, and $\mathrm{HPO}_{4}{ }^{2-}$ [30]. A triethylene teramine (TETA) functionalized magnetic poly (glycidyl methacrylate) (PGMA) nano-absorbent showed high selective adsorption for $\mathrm{Hg}(\mathrm{II})$ and good regeneration performance [31]. In brief, surprisingly high selectivity and efficiency of PGMA-based chelating adsorbents could be obtained by grafting specific functional groups.

In this work, we developed a new adsorbent by functionalizing PGMA with carboxymethyl to selectively absorb $\mathrm{Ag}(\mathrm{I})$ from wastewater. The adsorbent was characterized by X-ray photoelectron spectroscopy (XPS), Fourier transform infrared spectroscopy (FT-IR), zeta potential, and scanning electron microscopy (SEM). The effects of $\mathrm{pH}$, initial $\mathrm{Ag}(\mathrm{I})$ concentration, and reaction time were investigated. At the same time, the properties of the adsorbent were investigated by selectivity, reusability, thermodynamic, isotherms, and kinetics. The adsorption mechanisms were also studied.

\section{Materials and Methods}

\subsection{Materials}

Glycidyl methacrylate (GMA), azobisisobutyronitrile (AIBN), polyethyleneimine, bromoacetic acid (98\%), anhydrous ethanol (99\%) and polyvinyl pyrrolidone (PVP) were purchase from Aladdin Chemistry Co. Ltd., Shanghai, China. Sodium carbonate anhydrous, potassium carbonate, and carbon disulfide were obtained from Tianjin Chemical Reagent Co. Ltd., Tianjin, China. Silver Nitrate was purchased from Aladdin Chemistry Co. Ltd., Shanghai, China. All of the chemicals were analytical reagent. The $\mathrm{pH}$ value of solutions was adjusted by $\mathrm{HNO}_{3}$ and $\mathrm{NaOH}$ solutions.

\subsection{The Synthesis Process of Carboxymehyl Functionalized PGMA}

Scheme 1 presents the functionalization process of PGMA with carboxymethyl groups (BA-PGMA). Firstly, GMA (10.0 g), PVP ( $3.0 \mathrm{~g})$, and AIBN $(0.12 \mathrm{~g})$ were added to $150 \mathrm{~mL}$ of ethanol solution and the reaction was carried out at $70{ }^{\circ} \mathrm{C}$ for $5 \mathrm{~h}$ under $\mathrm{N}_{2}$ with stirring. After washing with ethanol for several times, the solid product (PGMA) was dried under vacuum at $50{ }^{\circ} \mathrm{C}$ for $24 \mathrm{~h}$. Second, PGMA ( $3 \mathrm{~g})$, polyethyleneimine $(6 \mathrm{~g})$ and ethanol $(100 \mathrm{~mL})$ were added to a three-necked flask. The mixture was stirred for $48 \mathrm{~h}$ at $70{ }^{\circ} \mathrm{C}$. Then, the suspension was centrifuged ( $9000 \mathrm{rpm}, 15 \mathrm{~min}$ ) and the precipitate was washed with ethanol and water until the water was neutral and then dried at $60{ }^{\circ} \mathrm{C}$ for $12 \mathrm{~h}$. The obtained product was referred to as PEL-PGMA. Then, PEL-PGMA $(2.5 \mathrm{~g})$, carbon disulfide $(1.0 \mathrm{~g})$, and potassium carbonate $(2.0 \mathrm{~g})$ were added to a three-necked flask containing $40 \mathrm{~mL}$ of deionized water. The mixture was stirred at room temperature for $12 \mathrm{~h}$. Then, the precipitate was 
washed with deionized water until the water was neutral and dried at $60^{\circ} \mathrm{C}$ for $12 \mathrm{~h}$. The product was defined as DTC-PGMA. Lastly, DTC-PGMA $(3.2 \mathrm{~g})$, deionized water $(40 \mathrm{~mL})$, sodium carbonate $(4.0 \mathrm{~g})$, and bromoacetic acid $(4.0 \mathrm{~g})$ were added into a three-necked flask. The mixture was stirred at $35^{\circ} \mathrm{C}$ for $12 \mathrm{~h}$. The suspension was then centrifuged and the precipitate was washed with deionized water until the filtrate was neutral. The final product was defined as BA-PGMA.<smiles>C=C(C)C(=O)OCC1CO1</smiles>

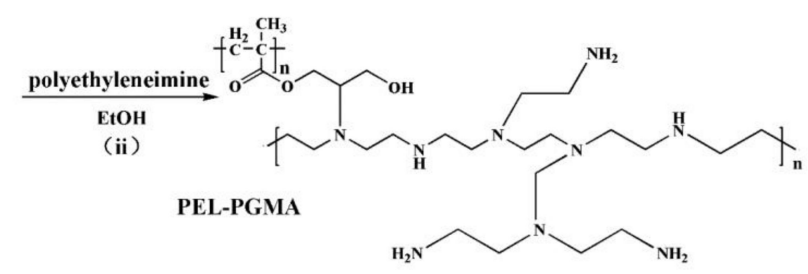

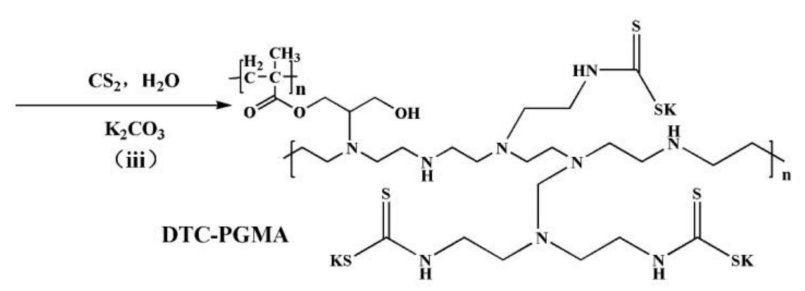

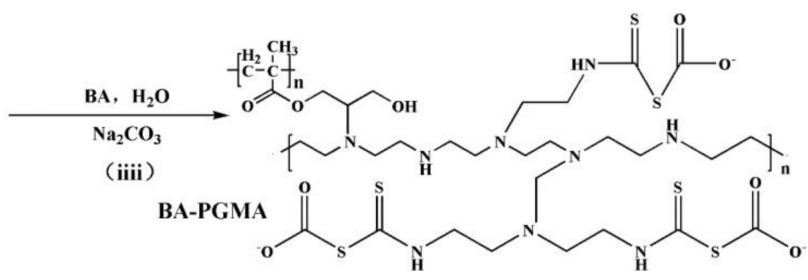

Scheme 1. The synthesis route of BA-PGMA (poly(glycidyl methacrylate) (PGMA) with carboxymethyl groups).

\subsection{Characterization}

The chemical forms of the functional groups were analyzed using FT-IR (Nicolet iS50, Thermo Scientific Co., Waltham, MA, USA) and XPS (ESCALab220i-XL, Thermo Scientific Co., Waltham, MA, USA). The microstructure of the sample was characterized by SEM and energy dispersive spectroscopy (EDS) (FEI/Philips XL30, Phenom ProX, Royal Dutch Philips Electronics Ltd., Amsterdam, The Netherlands). Zeta potential of the adsorbent was measured by a high sensitivity Zeta potential analyzer (Brookhaven Instruments Co., Austin, TX, USA). The concentrations of metal ions were detected by an inductively coupled plasma optical emission spectrometer (ICP) (Leeman Prodigy 7, Teledyne Leeman Labs., Hudson, NH, USA).

\subsection{Adsorption Experiment}

The experimental parameters included $\mathrm{pH}$, adsorption time, and initial $\mathrm{Ag}(\mathrm{I})$ concentration. An amount of $10 \mathrm{mg}$ of BA-PGMA was added to $15 \mathrm{~mL}$ of $\mathrm{Ag}(\mathrm{I})$ solution. The experiment was performed in a thermostatic steam bath shaker at an oscillating speed of $300 \mathrm{rpm}$ and at room 
temperature. The supernatant was separated and the concentration of $\mathrm{Ag}(\mathrm{I})$ in the solution was determined using ICP. The removal rate $(R)$ of $\mathrm{Ag}(\mathrm{I})$ was calculated by Equation (1):

$$
R=\frac{C_{\alpha}-C_{\beta}}{C_{\alpha}} \times 100 \%
$$

The adsorption capacity $(U)$ of $\mathrm{Ag}(\mathrm{I})$ on BA-PGMA at equilibrium was calculated by Equation (2):

$$
U=\frac{C_{\alpha}-C_{\beta}}{m} \times V
$$

Here, $C_{\alpha}(\mathrm{mg} / \mathrm{L})$ represented the initial concentration of $\mathrm{Ag}(\mathrm{I}), C_{\beta}(\mathrm{mg} / \mathrm{L})$ represented the concentration of $\mathrm{Ag}(\mathrm{I})$ after adsorption, $U$ represented the adsorption capacity. $V(\mathrm{~L})$ represented the volume and $\mathrm{m}(\mathrm{g})$ represented the mass of BA-PGMA.

\section{Results and Discussion}

\subsection{Characterization of BA-PGMA}

The FT-IR spectra of GMA, PGMA, PEL-PGMA, DTC-PGMA, and BA-PGMA are showed in Figure 1. The peaks at $751 \mathrm{~cm}^{-1}, 1161 \mathrm{~cm}^{-1}, 1252 \mathrm{~cm}^{-1}, 1727 \mathrm{~cm}^{-1}$ and $2945 \mathrm{~cm}^{-1}$ were attributed to the stretching vibrations of $\mathrm{C}-\mathrm{O}-\mathrm{C}, \mathrm{C}-\mathrm{O}, \mathrm{C}-\mathrm{C}, \mathrm{C}=\mathrm{O}$ and $\mathrm{C}-\mathrm{H}$, respectively [32]. The peak of $908 \mathrm{~cm}^{-1}$ was due to the epoxy group of GMA and PGMA. After reacting with polyethyleneimine, the epoxy group was opened, resulting in the disappearance of the epoxy peak. In the infrared spectrum of PEL-PGMA, DTCPGMA, and BA-PGMA, the new peak at $1474 \mathrm{~cm}^{-1}$ was due to the stretching vibration of $C-N$. The vibration belts at $3430 \mathrm{~cm}^{-1}$ and $1637 \mathrm{~cm}^{-1}$ were $\mathrm{O}-\mathrm{H}$ deformation vibration. The new peaks at $669 \mathrm{~cm}^{-1}$ and $1071 \mathrm{~cm}^{-1}$ were due to the stretching vibration of $C-S$ and $C=S$ of DTC-PGMA and BA-PGMA. For BA-PGMA, the O-H deformation vibrating at $3430 \mathrm{~cm}^{-1}$ and $1637 \mathrm{~cm}^{-1}$ was significantly enhanced due to the $\mathrm{C}-\mathrm{O}$ and $\mathrm{C}=\mathrm{O}$ bonds in acetic acid. The results indicated that BA-PGMA had been successfully synthesized.

X-ray photon spectroscopy was used to determine the chemical composition of the material. Figure 2 shows the peaks of N1s and S1s in the modified material. Figure 3 shows the C1s spectra. The C1s of PGMA presents the $\mathrm{C}-\mathrm{C}(286.2 \mathrm{eV}), \mathrm{O}-\mathrm{C}=\mathrm{O}(288.5 \mathrm{eV})$ and $\mathrm{C}-\mathrm{O}-\mathrm{C}(285.2 \mathrm{eV})$ groups (Figure 3a) [33]. After polyethyleneimine modification, a new C-N $(285.9 \mathrm{eV})$ peak appeared in PEL-PGMA (Figure 3b) [34]. Comparing with PEL-PGMA, DTC-PGMA shows the S-C=S bond $(286.2 \mathrm{eV}$ ) (Figure 3c) [35]. In BA-PGMA, the area of the $\mathrm{O}-\mathrm{C}=\mathrm{O}$ group was larger than that DTC-PGMA because the number of $\mathrm{O}-\mathrm{C}=\mathrm{O}$ groups increased (Figure $3 \mathrm{~d}$ ).

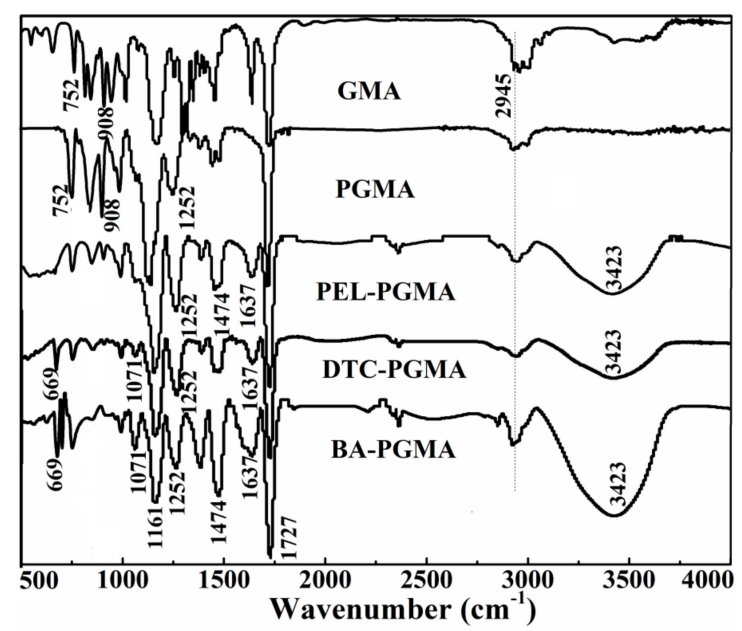

Figure 1. Fourier transform infrared spectroscopy (FT-IR) spectra of GMA, PGMA, PEL-PGMA, DTC-PGMA and BA-PGMA. 


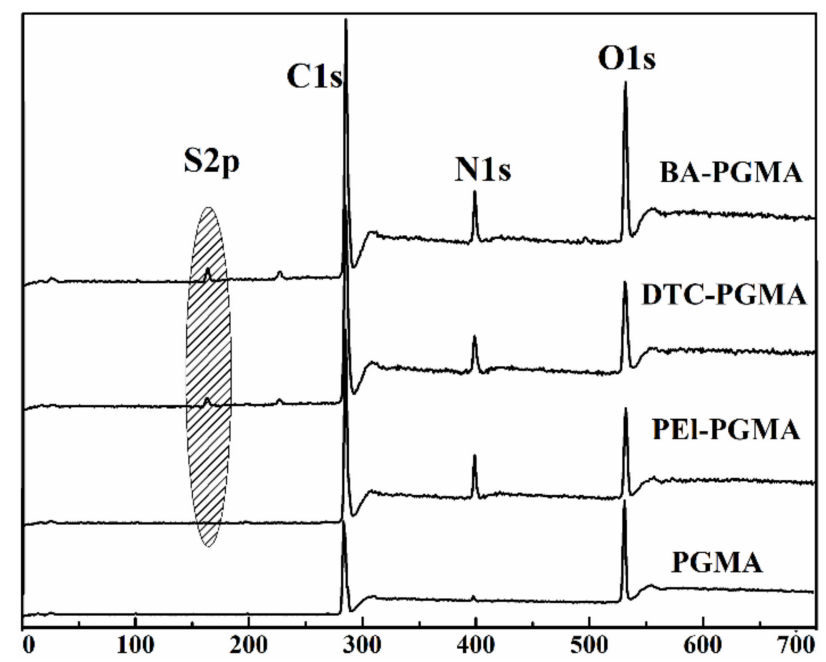

Figure 2. X-ray photoelectron spectroscopy (XPS) survey scan of PGMA, PEL-PGMA, DTC-PGMA, and BA-PGMA.
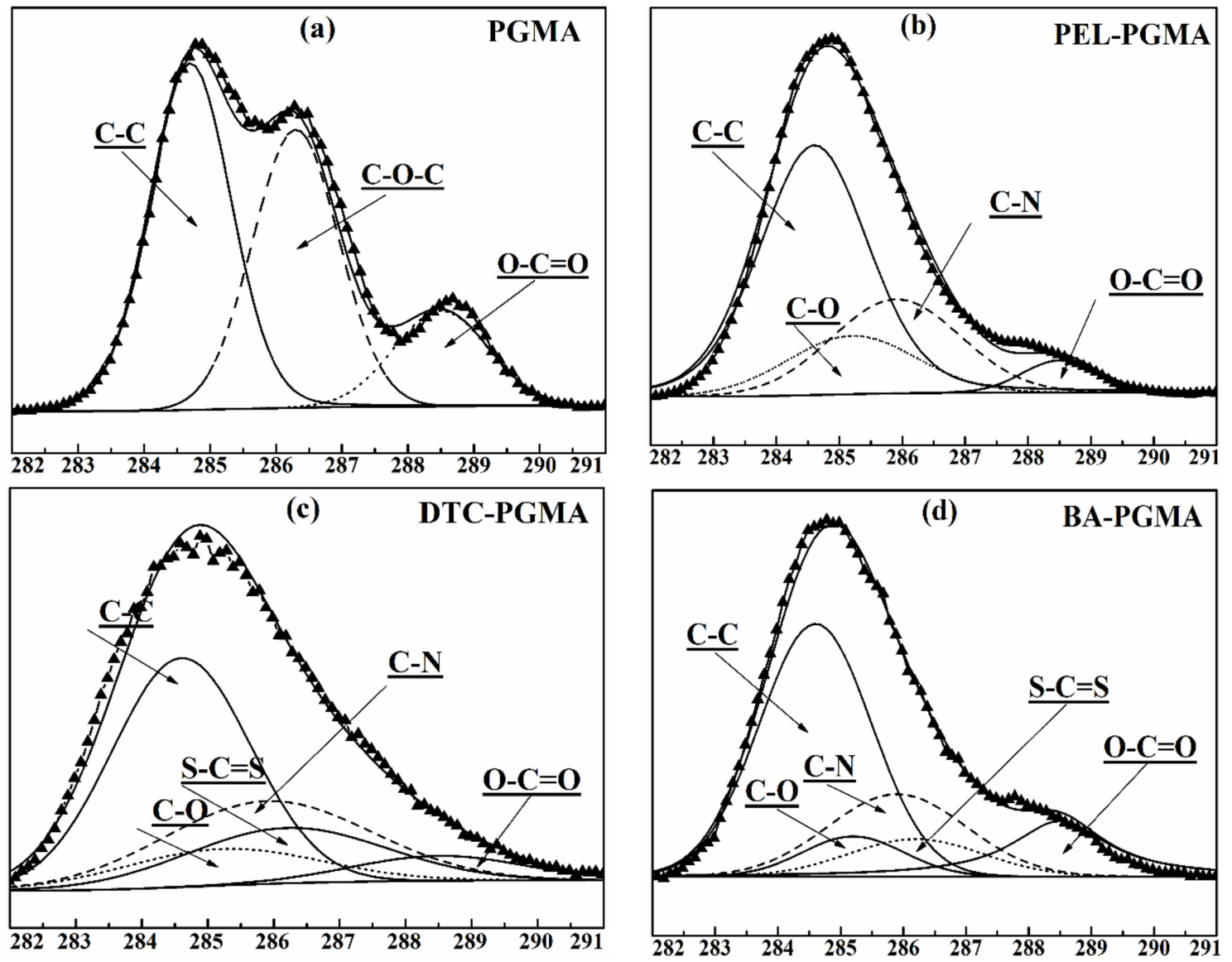

Figure 3. C1s spectra of PGMA (a), PEL-PGMA (b), DTC-PGMA (c), BA-PGMA (d).

\subsection{Effect of Experimental Parameters on Adsorption of $A g(I)$}

\subsubsection{Effect of $\mathrm{pH}$}

As one of the main factors affecting the adsorption of $\mathrm{Ag}(\mathrm{I})$ by BA-PGMA, the $\mathrm{pH}$ of the solution can promote the dispersion of the functional groups of the adsorbent and adjust the resulting electrostatic adsorption or complexation reaction. We studied the effect of solution $\mathrm{pH}$ values from 1 to 6 on the removal rate of $\operatorname{Ag}(\mathrm{I})$. The hydrolysis of $\mathrm{Ag}(\mathrm{I})$ occurs in the solution when the $\mathrm{pH}$ is 
greater than 6. An amount of $10 \mathrm{mg}$ of BA-PGMA was added to $15 \mathrm{~mL}$ of silver solution $(100 \mathrm{mg} / \mathrm{L})$, and oscillated for eight hours at room temperature. Then, the solution was centrifuged to determine the concentration of $\mathrm{Ag}(\mathrm{I})$. As shown in Figure 4a the removal rate of $\mathrm{Ag}^{+}$was relatively low when the $\mathrm{pH}$ was in the range of 1 to 2, and as the $\mathrm{pH}$ increased, the removal rate of Ag was improved and reached maximum $(76.4 \%)$ at $\mathrm{pH} 4$. So, we chose $\mathrm{pH} 4$ as the optimal $\mathrm{pH}$ in the following experiments. In order to verify the adsorption mechanism, Zeta potential was used to study the charge type of the BA-PGMA surface (Figure $4 \mathrm{~b}$ ). The isoelectric point of BA-PGMA was approximately 2.1, which revealed that the BA-PGMA adsorbent was positively charged at $\mathrm{pH}<2.1$ and negatively charged at $\mathrm{pH}>2.1$. Most of the amine groups on the adsorbent surface were protonated at $\mathrm{pH}<2.1$, which induced an electrostatic repulsion to the silver ions. There was no electrostatic attraction between BA-PGMA and Ag(I) at this time. The deprotonation of amine groups induced the electrostatic attraction toward the $\mathrm{Ag}^{+}$at $\mathrm{pH}>2$.1. In addition, at low $\mathrm{pH}$, the higher concentration of $\mathrm{H}^{+}$ions will compete with $\mathrm{Ag}^{+}$for the complex sites, resulting in the decrease of adsorption capacity of the silver ions [36]. In order to study the stability of BA-PGMA in acidic solution, BA-PGMA was soaked in an aqueous solution at $\mathrm{pH} 4$ for $24 \mathrm{~h}$. After filtering and drying, the soaked BA-PGMA was used to adsorb silver ions. The removal rate of silver ion by the soaked BA-PGMA was $71.7 \%$, which was close to that of BA-PGMA. Therefore, BA-PGMA is stable in acidic solution.
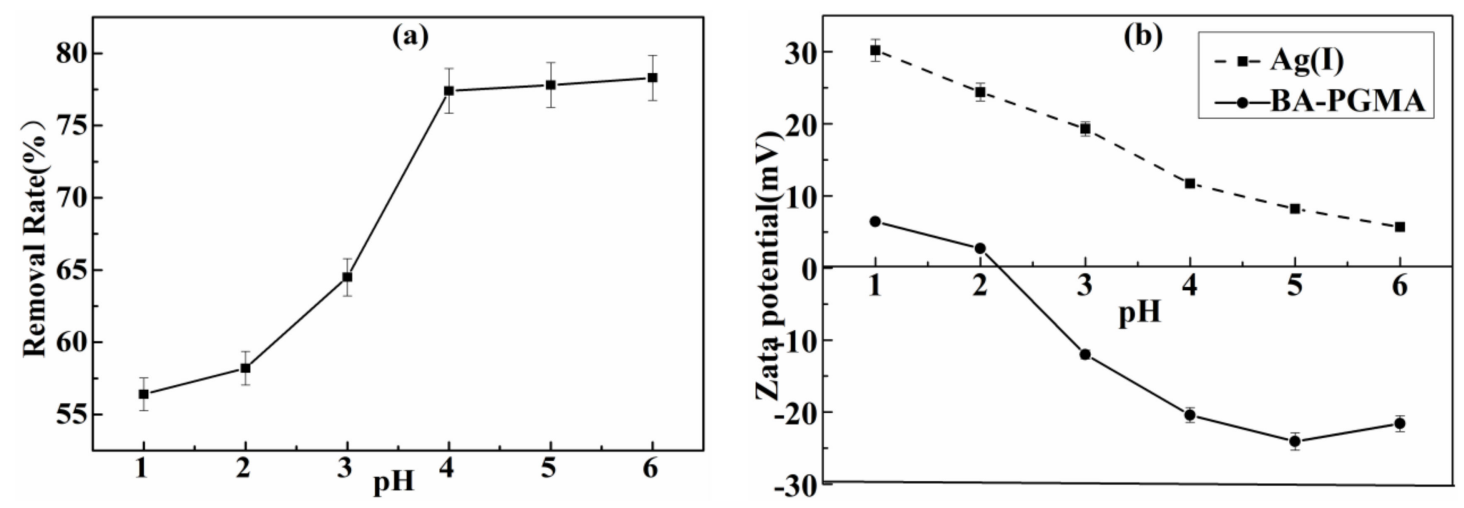

Figure 4. Effect of $\mathrm{pH}$ on the removal rate of $\mathrm{Ag}(\mathrm{I})(\mathbf{a})$ and zeta potential of BA-PGMA (b).

\subsubsection{Effect of Time on Adsorption Capacity of $\mathrm{Ag}(\mathrm{I})$ and Kinetics}

Figure 5 a shows the effect of adsorption time on the adsorption capacity of silver ions when the initial concentration is $100 \mathrm{mg} / \mathrm{L}$ at $\mathrm{pH}$ 4. In the first ten minutes, the adsorption rate of $\mathrm{Ag}(\mathrm{I})$ was very fast because there were enough active sites on BA-PGM. After ten minutes, the adsorption amount of $\mathrm{Ag}(\mathrm{I})$ gradually increased with time. The adsorption capacity increased slightly with the passage of time, and the adsorption reached equilibrium at $300 \mathrm{~min}$.
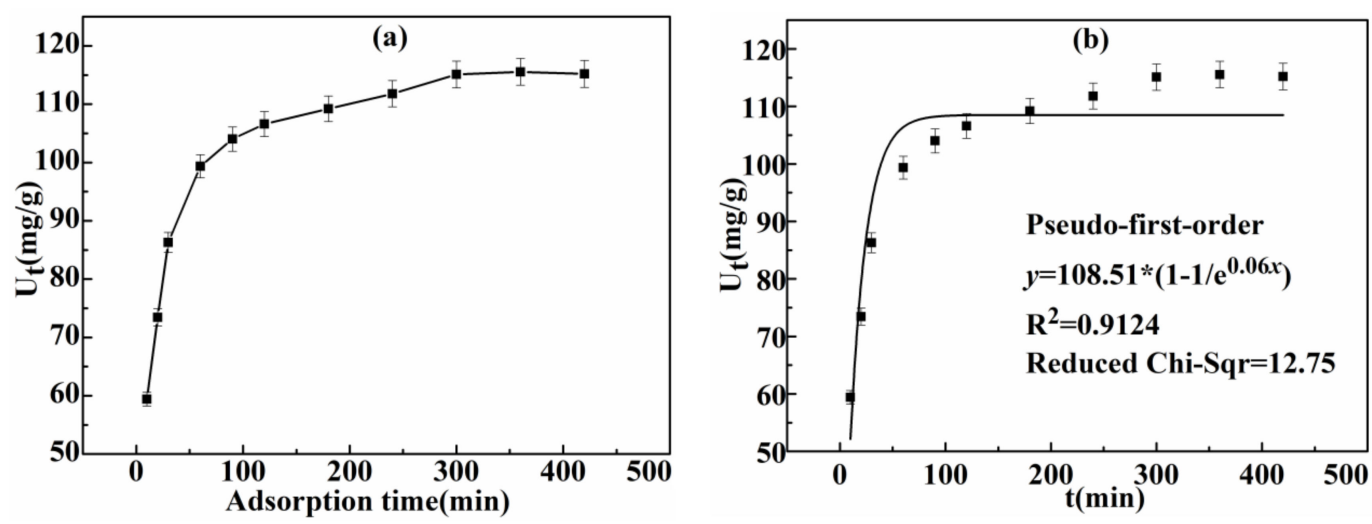

Figure 5. Cont. 

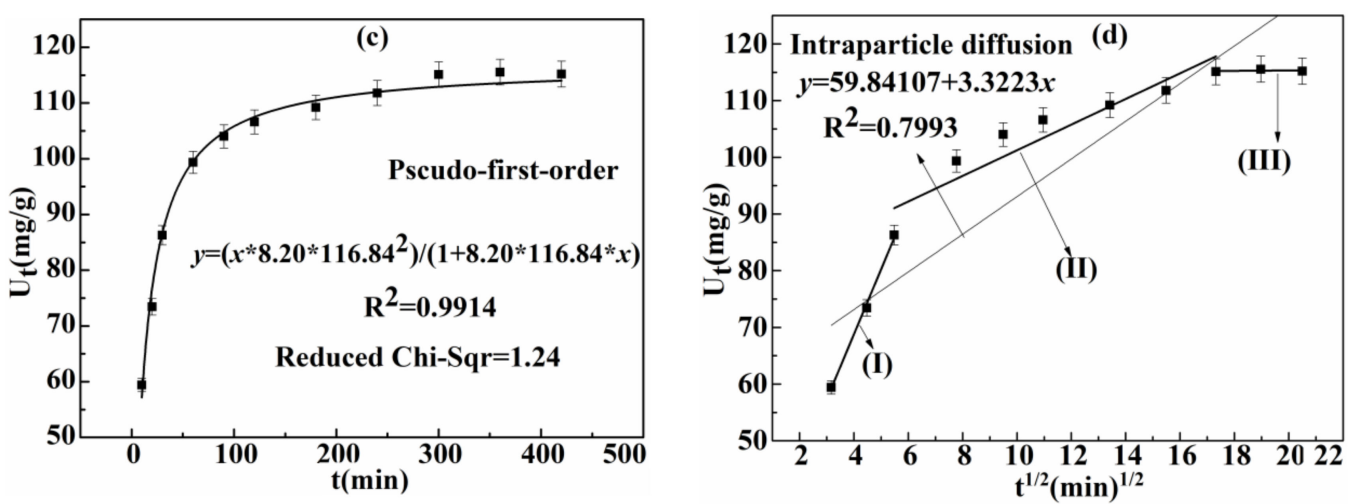

Figure 5. Effect of adsorption time on adsorption of Ag(I) by BA-PGMA (a) and kinetic model (pseudo-level (b), pseudo-secondary (c), intra-particle diffusion (d)).

We used the pseudo first-order, pseudo second-order and intraparticle diffusion kinetics model to study the adsorption mechanism. The pseudo-first-order model is mainly physical adsorption. The pseudo-first-order model assumed the occupancy of adsorption sites was directly proportional to the driving forces and the number of unoccupied sites, respectively [37]. The adsorption process explained by the pseudo second-order model was mainly chemical adsorption [38]. In order to determine whether the adsorption process of $\mathrm{Ag}(\mathrm{I})$ was related to the rate, the mechanism of intraparticle diffusion model was used [39]. The Equations (3)-(5) were the pseudo-first-order, pseudo-second-order, and intraparticle diffusion kinetic models, respectively:

$$
\begin{gathered}
U_{t}=U_{\mathrm{e}}\left(1-\frac{1}{\mathrm{e}^{K_{\mathrm{a}} t}}\right) \\
U_{t}=\frac{t \cdot K_{\mathrm{b}} \cdot U_{\mathrm{e}}{ }^{2}}{1+K_{\mathrm{b}} \cdot U_{\mathrm{e}} \cdot t} \\
U_{t}=K_{c} t^{1 / 2}+C
\end{gathered}
$$

where, $U_{\mathrm{e}}(\mathrm{mg} / \mathrm{g})$ was the equilibrium adsorption capacity; $U_{t}(\mathrm{mg} / \mathrm{g})$ was the uptake capacity at time $t(\min ) \cdot K_{\mathrm{a}}(\mathrm{g} /(\mathrm{mg} \cdot \mathrm{min}))$, and $K_{\mathrm{b}}(\mathrm{g} / \mathrm{mg} \cdot \mathrm{min})$ were the adsorption rate constants of pseudo-primary and pseudo-secondary models. $K_{c}\left(\mathrm{mg} / \mathrm{g} \cdot \mathrm{min}^{1 / 2}\right)$ was the intraparticle diffusion rate constant, and $C$ was relative to the liquid film thickness index.

The obtained experimental data were respectively fitted using three kinetic models (Figure $5 b-d$ ). The kinetic parameters for the three models are listed in Table 1. In contrast, the kinetics of BA-PGMA adsorption of $\mathrm{Ag}(\mathrm{I})$ was more consistent with the pseudo second-order model, because the $\mathrm{R}^{2}$ value (0.9914) of the pseudo-quadratic model was higher than those of other models. In addition, the adsorption capacity of the second-order model was $116.84 \mathrm{mg} / \mathrm{g}$, which was close to the experimental data $(117.15 \mathrm{mg} / \mathrm{g})$. These results demonstrate that the adsorption of $\mathrm{Ag}(\mathrm{I})$ conforms to the pseudo-secondary model, and the process was controlled by chemisorption. This means that the $\mathrm{Ag}(\mathrm{I})$ in the solution interacted with the functional groups on the BA-PGMA and they shared an electron pair with each other. In addition, the intraparticle diffusion model can be divided into three processes (Figure $5 \mathrm{~d}$ and Table 2). In stage I $(t \leq 30 \mathrm{~min}$ ), the adsorption capacity of $\mathrm{Ag}(\mathrm{I})$ increased rapidly because there were enough active sites on the surface of BA-PGMA. In the stage II ( $30 \leq t \leq 300 \mathrm{~min}$ ), the adsorption capacity of silver ion was reduced compared to the first stage, because the active sites decreased as the adsorption time increased. In stage III (300 $\mathrm{min} \leq t \leq 420 \mathrm{~min}$ ), the adsorption capacity was basically unchanged, and the adsorption equilibrium was reached. First, the fitting factor $\left(R^{2}\right)$ of the stage II was higher than the other two stages. At this stage, membrane diffusion (external mass transfer) dominates at the beginning. Then, after the active site of the BA-PGMA surface was saturated, $\mathrm{Ag}(\mathrm{I})$ migrates to the inner surface, and intraparticle diffusion controls the adsorption rate. 
In addition, the straight line fitted by these three stages does not pass through the origin. It can be concluded that the adsorption process was not a single process, and both surface adsorption and intraparticle diffusion processes affected the adsorption rate at different stages [40].

Table 1. Kinetic parameters for Ag(I) adsorption by BA-PGMA.

\begin{tabular}{cccccc}
\hline \multirow{2}{*}{ First-Order Model } & $K_{\mathrm{a}}(\mathrm{g} /(\mathrm{mg} \cdot \mathrm{min}))$ & $U_{\mathrm{e}}(\mathrm{mg} / \mathrm{g})$ & \multicolumn{2}{c}{$R^{2}$} & \multicolumn{2}{c}{ Reduced Chi-Square } \\
& 0.06 & 108.51 & \multicolumn{2}{c}{0.9124} & 12.75 \\
\hline \multirow{2}{*}{ Second-Order Model } & $K_{\mathrm{b}}(\mathrm{g} /(\mathrm{mg} \cdot \mathrm{min}))$ & $U_{\mathrm{e}}(\mathrm{mg} / \mathrm{g})$ & $R^{2}$ & \multicolumn{2}{c}{ Reduced Chi-Square } \\
& \multicolumn{2}{c}{8.20} & \multicolumn{2}{c}{116.84} & \multicolumn{2}{c}{$R^{2}$} \\
\multirow{2}{*}{ Intra-Particle Diffusion Model } & \multicolumn{2}{c}{$K_{c}\left(\mathrm{mg} /\left(\mathrm{g} \cdot \mathrm{min}^{1 / 2}\right)\right.$} & \multicolumn{2}{c}{0.7993} \\
\hline
\end{tabular}

Table 2. The parameters of the three stages of the I-R model.

\begin{tabular}{cccc}
\hline Stage & $\boldsymbol{K}_{\boldsymbol{c}}$ & $\boldsymbol{R}^{\mathbf{2}}$ & $\boldsymbol{C}$ \\
\hline I & 11.46 & 0.9953 & 22.95 \\
II & 2.16 & 0.8583 & 78.62 \\
III & 0.03 & -0.8881 & 114.61 \\
\hline
\end{tabular}

\subsubsection{Effect of Initial Concentration of $\mathrm{Ag}(\mathrm{I})$ and Adsorption Isotherm}

In order to study the effect of the initial silver ion concentration on the adsorption, $10 \mathrm{mg}$ of BA-PGMA was added to a series of $15 \mathrm{~mL} \mathrm{Ag(I)} \mathrm{solutions} \mathrm{with} \mathrm{different} \mathrm{concentrations} \mathrm{at} \mathrm{pH} 4$. As shown in Figure 6a, the absorption capacity of $\mathrm{Ag}(\mathrm{I})$ gradually increased with the increase of the silver ion concentration. At a concentration of $300 \mathrm{mg} / \mathrm{L}$, adsorption equilibrium was reached. Above this value, there was no significant change in the adsorption capacity of $\mathrm{Ag}(\mathrm{I})$. When the $\mathrm{Ag}(\mathrm{I})$ concentration was less than $300 \mathrm{mg} / \mathrm{L}$, there were enough active adsorption sites on the surface of BA-PGMA to adsorb $\operatorname{Ag}(\mathrm{I})$. When the $\mathrm{Ag}(\mathrm{I})$ concentration was more than $300 \mathrm{mg} / \mathrm{L}$, the available adsorption sites of $\mathrm{Ag}(\mathrm{I})$ were saturated, and there was no active site for $\mathrm{Ag}(\mathrm{I})$ adsorption. The maximum uptake of silver was $157.05 \mathrm{mg} / \mathrm{L}$, indicating that BA-PGMA was an effective adsorbent for $\mathrm{Ag}(\mathrm{I})$. It shows it has a great potential and application value in the recovery of $\mathrm{Ag}(\mathrm{I})$.

Adsorption isotherms can indicate the interaction mechanism between BA-PGMA and Ag(I), as well as the change of adsorption capacity with the concentration of the adsorbed species. The adsorption capacity and equilibrium concentration of $\mathrm{Ag}(\mathrm{I})$ at $298 \mathrm{~K}$ and $\mathrm{pH} 4$ were described using the Freundlich, Langmuir, Temkin, Hill, D-R isothermal models. The Freundlich isotherm model has a wide range of applications in certain areas. This model assumes that the adsorption is a multilayer sorption on heterogeneous surfaces and describes that the adsorption is non-ideal and reversible [41]. The linear mathematical expression is as shown in the Equation (6). $U_{\mathrm{e}}, C_{\beta}$, and $K_{\mathrm{h}}$ represented the equilibrium adsorption capacity and concentration of $\mathrm{Ag}(\mathrm{I})$ after adsorption and the constant of this model. The slope $1 / \mathrm{n}$ is an indicator of adsorption intensity of surface heterogeneity [42].
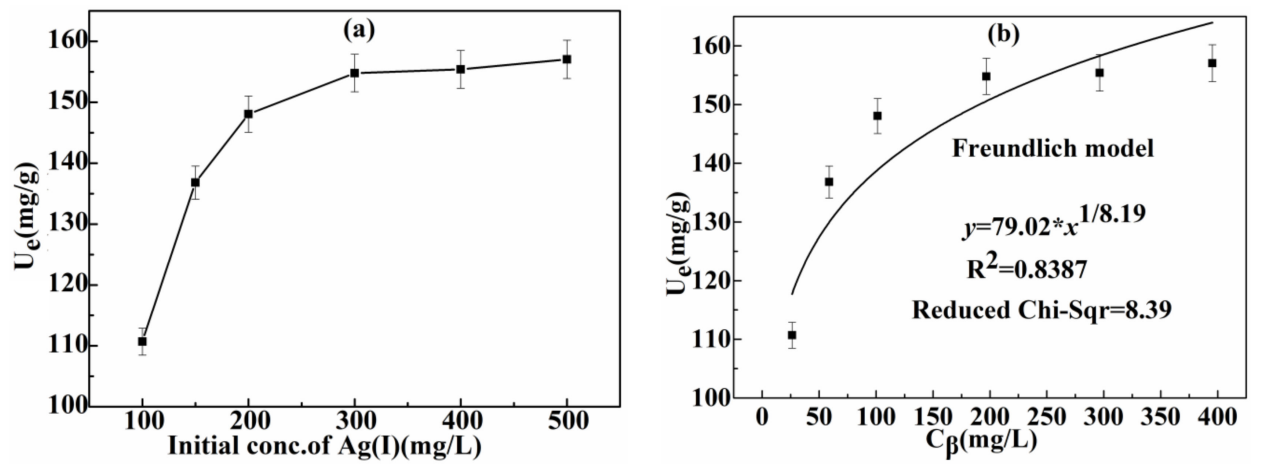

Figure 6. Cont. 

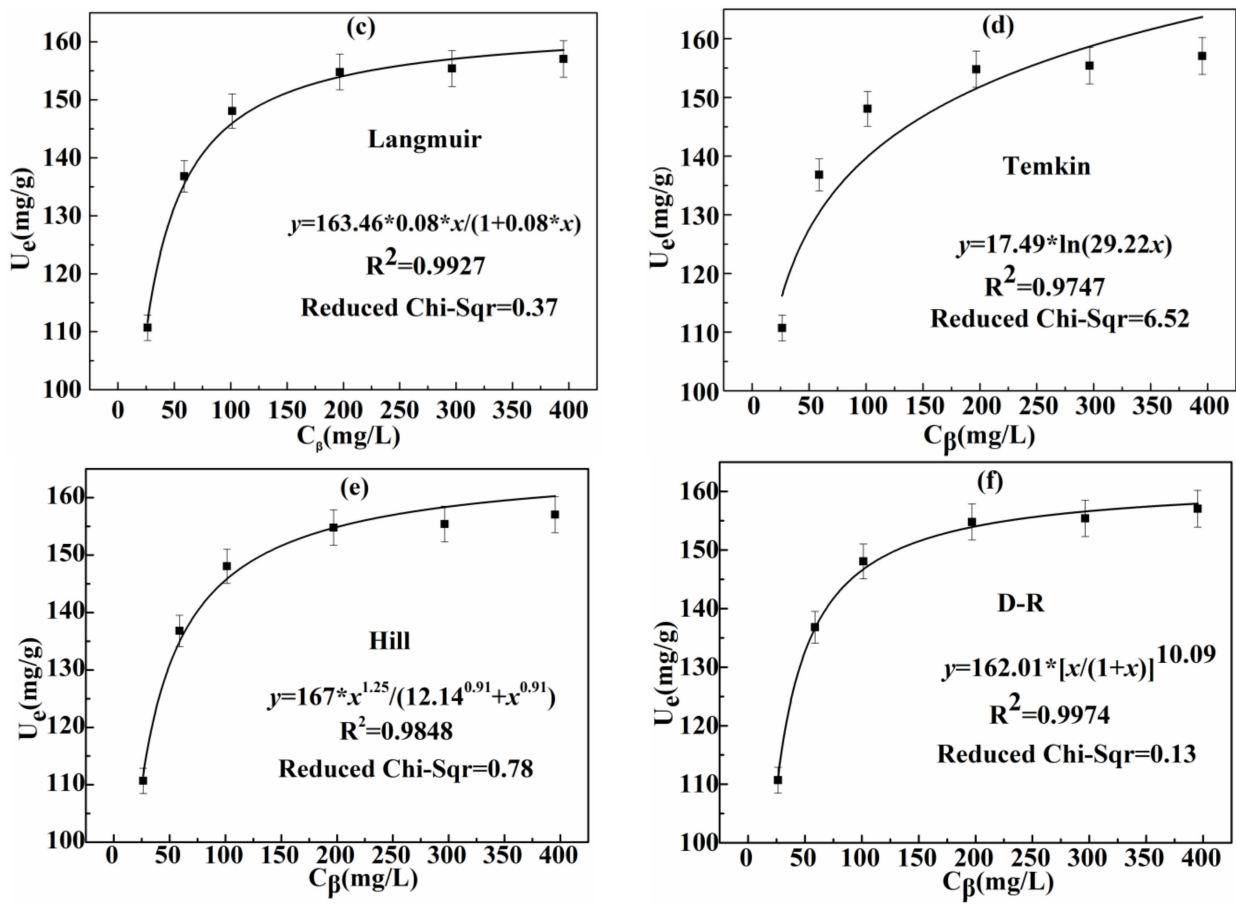

Figure 6. Effect of initial concentration of $\operatorname{Ag}(\mathrm{I})(\mathbf{a})$, adsorption isotherm, Freundlich (b), Langmuir (c), Temkin (d), Hill (e), and D-R (f).

$$
U_{\mathrm{e}}=K_{\mathrm{h}} \cdot C_{\beta} 1 / n_{1}
$$

The Langmuir isotherm model explained that the adsorption process was a monolayer adsorption on the homogeneous surfaces. Its equation was used to evaluate the adsorption capacities of the adsorbents [43]. The nonlinear expression of Langmuir is shown in Equation (7). Where $K_{i}$ was the constant of this model and $U_{\mathrm{m}}(\mathrm{mg} / \mathrm{g})$ was the monolayer adsorption capacity of $\mathrm{Ag}(\mathrm{I})$. It was also the maximum adsorption capacity of single layer adsorption.

$$
U_{\mathrm{e}}=\frac{U_{\mathrm{m}} \cdot K_{i} \cdot C_{\beta}}{1+K_{\mathrm{i}} \cdot C_{\beta}}
$$

Adsorption heat linearly decreased from the reaction between the adsorbate and the adsorbent under Temkin isotherm conditions [44]. The mathematical expression of this model is Equation (8). $V_{T}$ and $K_{\mathrm{j}}$ are the constants of the Temkin model.

$$
U_{\mathrm{e}}=V_{T} \cdot \ln \left(K_{\mathrm{j}} \cdot C_{\beta}\right)
$$

The Hill isothermal model assumes that one active site can absorb multiple ions, indicating a driving relationship between different adsorbates on the same uniform surface and the binding sites [45]. The nonlinear expression of the Hill mode is shown in Equation (9). Here, $K_{\mathrm{L}}$ and $N$ are the constants of this model.

$$
U_{\mathrm{e}}=\frac{U_{\mathrm{m}} \cdot C_{\beta}{ }^{N}}{1+K_{\mathrm{L}} \cdot C_{\beta}{ }^{N}}
$$

The D-R model can be used to indicate the adsorption characteristics and the free energy of the adsorbate. It can also be used to analyze adsorption mechanisms on homogeneous or heterogeneous surfaces [46]. The nonlinear expression of the model is shown in Equation (10). Here, $\omega$ and $U_{m}$ are the maximum adsorption capacity and constant, respectively. In addition, the free energy of adsorbed ions per molecule can be calculated by Equation (11). Free energy $(E)$ was used to determine whether 
the adsorption process was physical or chemical adsorption. The value of $1-8 \mathrm{~kJ} / \mathrm{mol}(E)$ explains that the adsorption is a physical process, $8-16 \mathrm{~kJ} / \mathrm{mol}$ indicates that the adsorption is electrostatic interaction, and the chemical adsorption results in $>16 \mathrm{~kJ} / \mathrm{mol}$.

$$
\begin{gathered}
U_{\mathrm{e}}=U_{\mathrm{m}} \cdot\left(\frac{C_{\beta}}{1+C_{\beta}}\right)^{\omega R T} \\
E=\frac{1}{\sqrt{2 \omega}}
\end{gathered}
$$

Figure 6 shows five models (Freundlich, Langmuir, Temkin, Hill, and D-R). Table 3 lists the relevant parameters for the five models. By comparing the five models, it can be found that the correlation coefficient values of Langmuir and D-R were relatively close $\left(R^{2} \mathrm{~L}=0.9927, R^{2} \mathrm{D}=0.9974\right)$ and greater than these of the other models. The maximum adsorption capacity $\left(\mathrm{U}_{\mathrm{m}}\right)$ calculated by the Langmuir model and the D-R model was $163.46 \mathrm{mg} / \mathrm{g}$ and $162.01 \mathrm{mg} / \mathrm{g}$, which was close to the experimental data $(157.05 \mathrm{mg} / \mathrm{g})$. Therefore, the Langmuir and D-R models are in line with this study. It indicated that the active adsorption sites on BA-PGMA were homogeneous. At the same time, the value of free energy $\omega$ in the D-R model was $11.04 \mathrm{~kJ} / \mathrm{mol}$, indicating that the adsorption mechanism was electrostatic interaction or chelation.

To further investigate the adsorption process, the Langmuir isotherm model was used to estimate the value of the separation factor constant $\left(R_{\mathrm{L}}\right)$ and to demonstrate the applicability of BA-PGMA to ions during adsorption. When $R_{\mathrm{L}}>1$ it was not applicable, $R=1$ it was linear, $0<R<1$ it was applicable and $R=0$ it was irreversible [47]. The mathematical expression for the coefficient $R_{\mathrm{L}}$ is as shown in Equation (12).

$$
R_{\mathrm{L}}=\frac{1}{1+K_{\mathrm{s}} \cdot C_{\alpha}}
$$

Here, $C_{\alpha}$ is the initial concentration of silver ions and $K_{\mathrm{s}}$ is a constant. The $R_{\mathrm{L}}$ values for different initial $\mathrm{Ag}(\mathrm{I})$ concentrations are listed in Table 4, all of which are greater than zero and less than one. As the concentration of $\mathrm{Ag}(\mathrm{I})$ increases, the $R_{\mathrm{L}}$ value decreases gradually, indicating that the higher the

\begin{tabular}{|c|c|c|c|c|}
\hline \multirow{2}{*}{ Freundlich } & \multirow{2}{*}{$\begin{array}{c}K_{\mathrm{h}} \\
79.02\end{array}$} & \multirow{2}{*}{$\begin{array}{c}n \\
8.19\end{array}$} & \multirow[t]{2}{*}{$R^{2}$} & Reduced Chi-Sqr \\
\hline & & & & 0.8387 \\
\hline \multirow{2}{*}{ Langmuir } & $U_{\mathrm{m}}(\mathrm{mg} / \mathrm{g})$ & $K_{i}$ & $R^{2}$ & Reduced Chi-Sqr \\
\hline & 163.46 & 0.08 & & $0.9927 \quad 0.37$ \\
\hline \multirow{2}{*}{ Temkin } & $K_{j}$ & $V_{T}$ & $R^{2}$ & Reduced Chi-Sqr \\
\hline & 29.22 & 17.49 & & $0.8747 \quad 6.52$ \\
\hline \multirow{2}{*}{ Hill } & $K_{\mathrm{L}}$ & $N$ & $R^{2}$ & Reduced Chi-Sqr \\
\hline & 12.14 & 0.91 & & 0.9848 \\
\hline \multirow{2}{*}{ D-R } & $\omega$ & $E(\mathrm{kj} / \mathrm{mol})$ & $R^{2}$ & Reduced Chi-Sqr \\
\hline & 0.0041 & 11.04 & & 0.9974 \\
\hline
\end{tabular}
concentration of $\operatorname{Ag}(\mathrm{I})$, the more favorable the adsorption.

Table 3. Adsorption isotherms parameters for Ag(I) on BA-PGMA.

Table 4. The Langmuir-based $R_{\mathrm{L}}$.

\begin{tabular}{cc}
\hline$C_{\alpha}(\mathrm{mg} / \mathrm{L})$ & $\boldsymbol{R}_{\mathbf{L}}$ \\
\hline 100 & 0.0808 \\
150 & 0.0554 \\
200 & 0.0421 \\
300 & 0.0285 \\
400 & 0.0215 \\
500 & 0.0172 \\
\hline
\end{tabular}


Table 5 lists the maximum adsorption capacities reported for other adsorbents in the literature. It can be seen that the BA-PGMA adsorbent has a large adsorption capacity for $\mathrm{Ag}(\mathrm{I})$ and has great potential in the field of recycling and utilization of $\mathrm{Ag}(\mathrm{I})$.

Table 5. Comparison of the adsorption amount of $\mathrm{Ag}(\mathrm{I})$ and adsorbent reported in the literature.

\begin{tabular}{ccc}
\hline Sorbent & $\boldsymbol{U}_{\mathbf{m}}(\mathbf{m g} / \mathbf{g})$ & Reference \\
\hline Natural Clinoptilolites & 31.44 & {$[48]$} \\
Active carbon & 32.80 & {$[49]$} \\
Nanocelluloses and their phosphorylated derivatives & 56 & {$[50]$} \\
MFT chelating resin & 60.05 & {$[51]$} \\
Bentonite clay & 61.48 & {$[52]$} \\
Ion-imprinted chitosan gel beads & 80.50 & {$[53]$} \\
$\mathrm{Ag}^{+}$-imprinted chitosan gel bead & 89.20 & {$[54]$} \\
Valonia tannin resin & 97.08 & {$[55]$} \\
BA-PGMA & 157.05 & This work \\
\hline
\end{tabular}

\subsubsection{Selectivity of BA-PGMA for $\mathrm{Ag}(\mathrm{I})$}

The effect of impurity ions on the adsorption of silver ions was studied. An amount of $10 \mathrm{mg}$ of BA-PGMA was added to $15 \mathrm{~mL}$ of the mixed ionic solutions (Ni(II), $\mathrm{Cu}(\mathrm{II}), \mathrm{Ni}(\mathrm{II}), \mathrm{Zn}(\mathrm{II})$ and $\mathrm{Ag}(\mathrm{I})$ ) at $\mathrm{pH}$ 4. The concentration of each ion was $100 \mathrm{mg} / \mathrm{L}$. The mixed solution was shaken at room temperature for $12 \mathrm{~h}$. It can be seen that the adsorption capacity of other ions is small except for copper ions (Figure 7). Table 6 lists the selectivity parameters for the different ions. The distribution factor $\left(K_{\mathrm{f}}\right)$ and the selectivity coefficient $(K)$ can be calculated by Equations (13) and (14). By comparison, the adsorption of $\mathrm{Ag}(\mathrm{I})$ on BA-PGMA showed a high distribution factor and selectivity coefficient. This further demonstrates that BA-PGMA has good selectivity for Ag(I) adsorption.

$$
\begin{gathered}
K_{\mathrm{f}}=\frac{U}{C_{\beta}}=\frac{C_{\alpha}-C_{\beta}}{C_{\beta}} \times \frac{V}{m} \times 1000 \\
K=\frac{K_{\mathrm{f}\left(\mathrm{Ag}^{+}\right)}}{K_{\mathrm{f}(\text { coexisting-ions })}}
\end{gathered}
$$

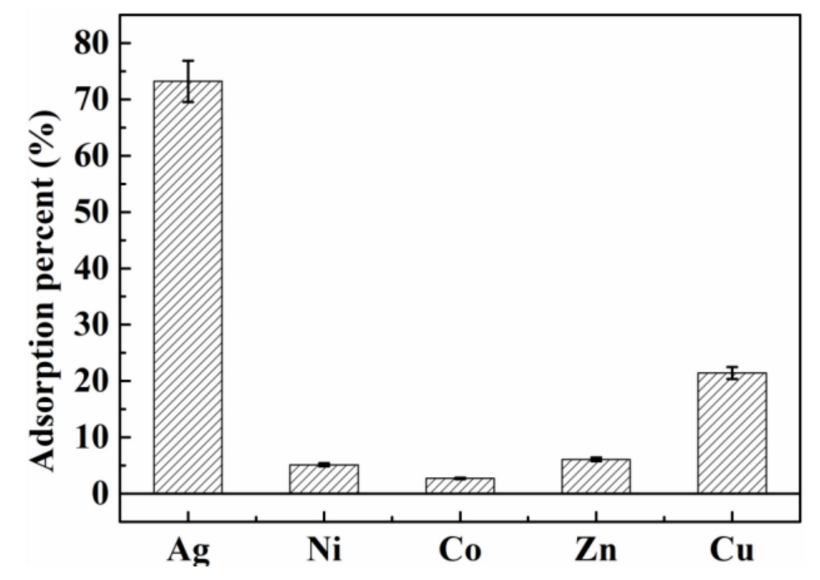

Figure 7. Effect of coexisting ion on the adsorption of Ag(I) by BA-PGMA. 
Table 6. The values of $K_{\mathrm{f}}$ and $K$ of coexisting ions.

\begin{tabular}{ccc}
\hline Coexisting Ions & $\boldsymbol{K}_{\mathbf{f}}(\mathbf{m L} / \mathbf{g})$ & $\boldsymbol{K}$ \\
\hline $\mathrm{Ag}^{+}$ & 4097.0 & - \\
$\mathrm{Ni}^{2+}$ & 81.3 & 50.4 \\
$\mathrm{Co}^{2+}$ & 41.9 & 97.8 \\
$\mathrm{Zn}^{2+}$ & 97.4 & 42.1 \\
$\mathrm{Cu}^{2+}$ & 409.1 & 10.0 \\
\hline
\end{tabular}

\subsubsection{Reuse Performance of BA-PGMA}

To test the reusability, $50 \mathrm{mg}$ of BA-PGMA was added to a $75 \mathrm{~mL} \mathrm{Ag(I)} \mathrm{solution} \mathrm{with} \mathrm{a}$ concentration of $100 \mathrm{mg} / \mathrm{L}$ at $\mathrm{pH} 4$, and the mixed solution was shaken for $12 \mathrm{~h}$. After centrifugation, the residue was eluted with a desorbent for $18 \mathrm{~h}$ and washed five times with distilled water. The desorbent consisted of nitric acid $(3 \mathrm{~mol} / \mathrm{L})$ and thiourea $(1.5 \mathrm{~mol} / \mathrm{L})$. After the experiment, four replicate experiments were performed. Figure 8 shows the reuse effect of BA-PGMA. After four repeated experiments, the removal rate of $\mathrm{Ag}(\mathrm{I})$ decreased slightly from $79.29 \%$ to $65.01 \%$. This proves that BA-PGMA has good reusability and can be effectively used for silver recovery for at least four cycles.

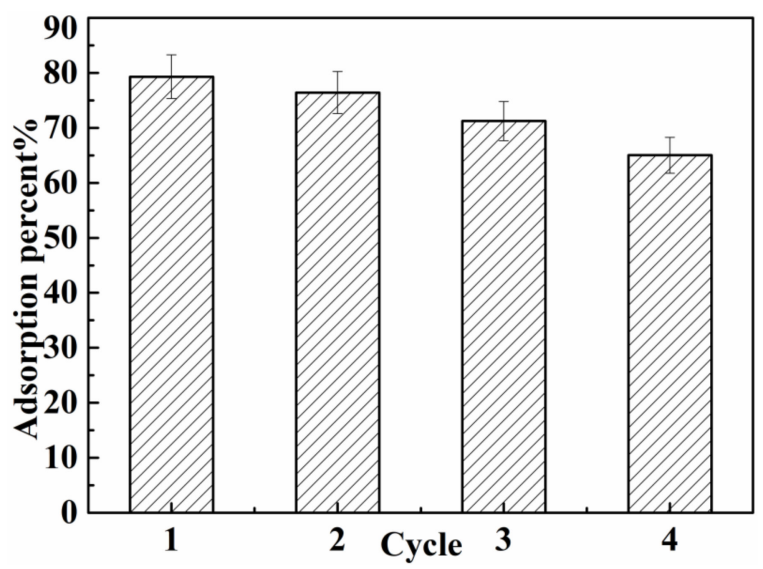

Figure 8. Reusability of BA-PGMA adsorbents.

The desorption isotherms were used further to investigate the desorption process and the reaction mechanism. Since the adsorption process conforms to the Langmuir model, the model was also used to deal with the desorption process, Equation (15) [56]. $C_{\beta}, U_{\mathrm{e}}$, and $U_{\mathrm{m}}$ represent the residual concentration of silver ions after adsorption, the adsorption capacity, and single-layer adsorption capacity of silver ions after equilibrium, respectively. $K_{\mathrm{o}}$ was a constant. The fitting results are showed in Figure 9. By comparison, it can be found that the $\mathrm{R}$ values of adsorption (0.9993) and desorption (0.9947) were very close, demonstrating that $\mathrm{Ag}(\mathrm{I})$ and the desorbent competed for the active sites on BA-PGMA at the same time [57]. In addition, because the desorbent is charged, it will electrostatically interact with $\mathrm{Ag}(\mathrm{I})$, reducing the interaction between BA-PGMA and $\mathrm{Ag}(\mathrm{I})$ [58]. It was concluded that the adsorbed $\mathrm{Ag}(\mathrm{I})$ was successfully desorbed by desorbent.

$$
\frac{C_{\beta}}{U_{\mathrm{e}}}=\frac{1}{U_{\mathrm{m}} \cdot K_{\mathrm{o}}}+\frac{C_{\beta}}{U_{\mathrm{m}}}
$$



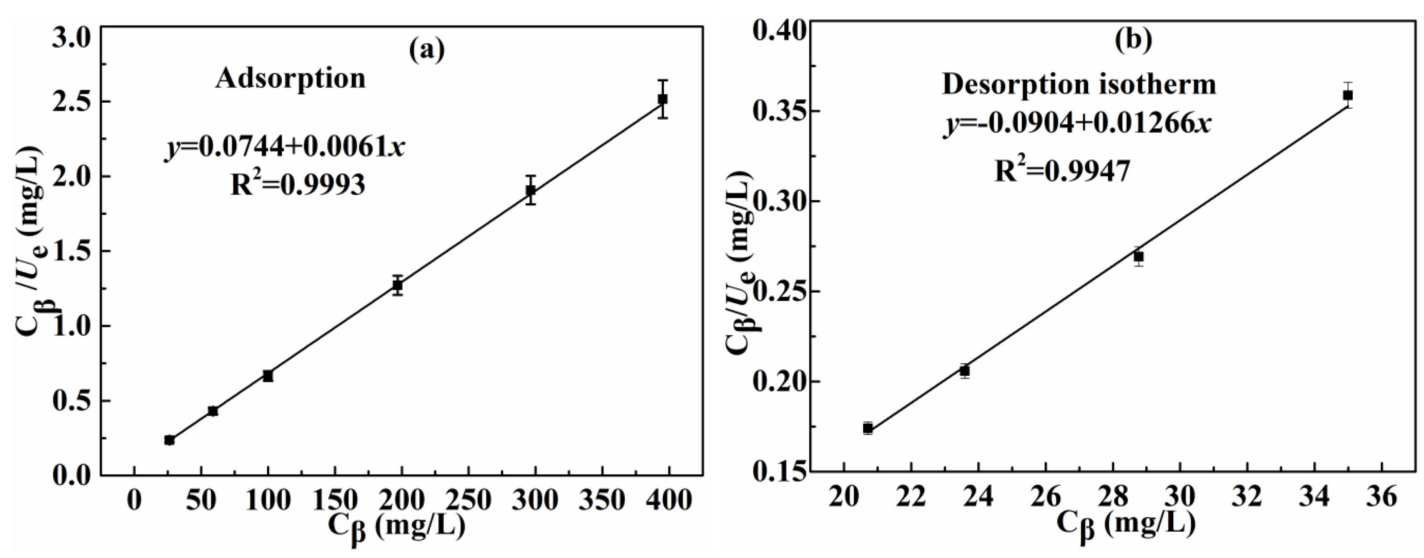

Figure 9. Linear Langmuir plot of adsorption (a) and desorption of BA-PGMA (b).

\subsubsection{Adsorption Mechanism of Ag(I) by BA-PGMA}

In order to further study the adsorption mechanism of BA-PGMA for Ag(I), BA-PGMA and BA-PGMA-Ag (Ag(I) loaded BA-PGMA defined as BA-PGMA-Ag) were analyzed by SEM and EDS. The results are shown in Figure 10. As can be seen from Figure 10a,b, the BA-PGMA and BA-PGMA-Ag diameters were in the range of 0.1 to $1 \mu \mathrm{m}$. The BA-PGMA and BA-PGMA-Ag were scanned by EDS. The scanning energy spectrum is shown in Figure 10c,d. The silver content on BA-PGMA-Ag is very high. Therefore, the combination of $\mathrm{Ag}(\mathrm{I})$ with $\mathrm{N}, \mathrm{O}, \mathrm{S}$ was very good, indicating that $\mathrm{N}, \mathrm{O}$. and $\mathrm{S}$ played an important role in the adsorption process.

The XPS analysis of BA-PGMA was carried out before and after the adsorption of Ag(I). Figure 11a is the total spectrum before and after adsorption. The binding energies at $367.8 \mathrm{eV}$ and $374.2 \mathrm{eV}$ were assigned to Ag3d in BA-PGMA-Ag, which were much lower than that of $\mathrm{AgNO}_{3}$ [59]. This shows that the electron density was higher than that of free $\mathrm{Ag}(\mathrm{I})$. So, $\mathrm{Ag}(\mathrm{I})$ participates in the coordination reaction. The binding energy of the N1s group of BA-PGMA and BA-PGMA-Ag is shown in Figure 11c,d. The bonds at $399.1 \mathrm{eV}$ and $400.69 \mathrm{eV}$ represent $-\mathrm{NH}$ and $\mathrm{HN}_{2}{ }^{+}$in BA-PGMA, respectively. The binding energy of $\mathrm{NH}_{2}{ }^{+}$in BA-PGMA-Ag was located at $400.92 \mathrm{eV}$ because $\mathrm{Ag}(\mathrm{I})$ covalently bonded with $\mathrm{N}$ through lone-pairs electrons. The S2p spectra of BA-PGMA and BA-PGMA-Ag are shown in Figure $11 \mathrm{e}, \mathrm{f}$. The binding energy of $\mathrm{S}_{1 / 2}$ and $\mathrm{S}_{3 / 2}$ was shifted from $162.57 \mathrm{eV}$ and $164.1 \mathrm{eV}$, to $162.69 \mathrm{eV}$ and $163.8 \mathrm{eV}$, because chelation with $\mathrm{Ag}(\mathrm{I})$ and silver thiolate was produced. In Figure 11g,h, the peaks at $531.09 \mathrm{eV}$ and $532.09 \mathrm{eV}$ correspond to the binding energies of $\mathrm{O}-\mathrm{C}=\mathrm{O}$ and $\mathrm{C}-\mathrm{O}-\mathrm{H}$, respectively. Due to the coordination with $\mathrm{Ag}(\mathrm{I})$, the potential at $532.09 \mathrm{eV}$ for C-O-H in BA-PGMA shifted to $532.82 \mathrm{eV}$ in BA-PGMA-Ag [60]. The main mechanism is electrostatic interaction and chelation (Scheme 2).

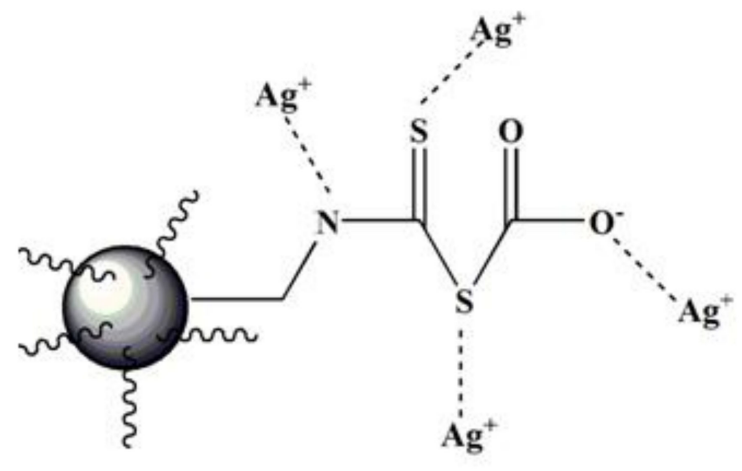

Electrostatic interaction or Chelation interaction

Scheme 2. Mechanism of the adsorption of Ag(I) onto BA-PGMA. 

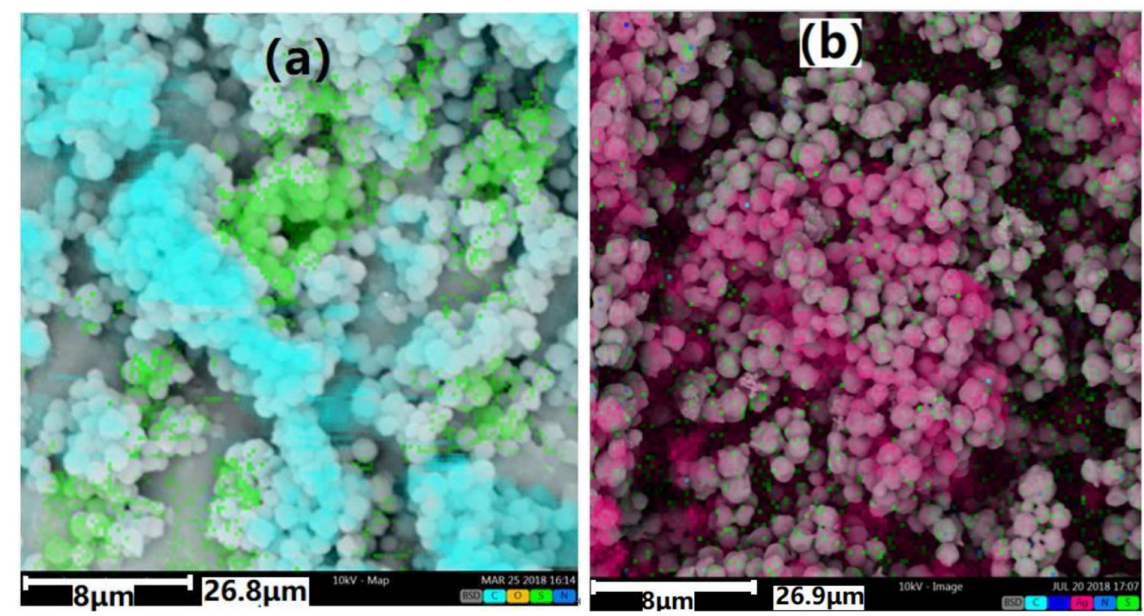

(c)
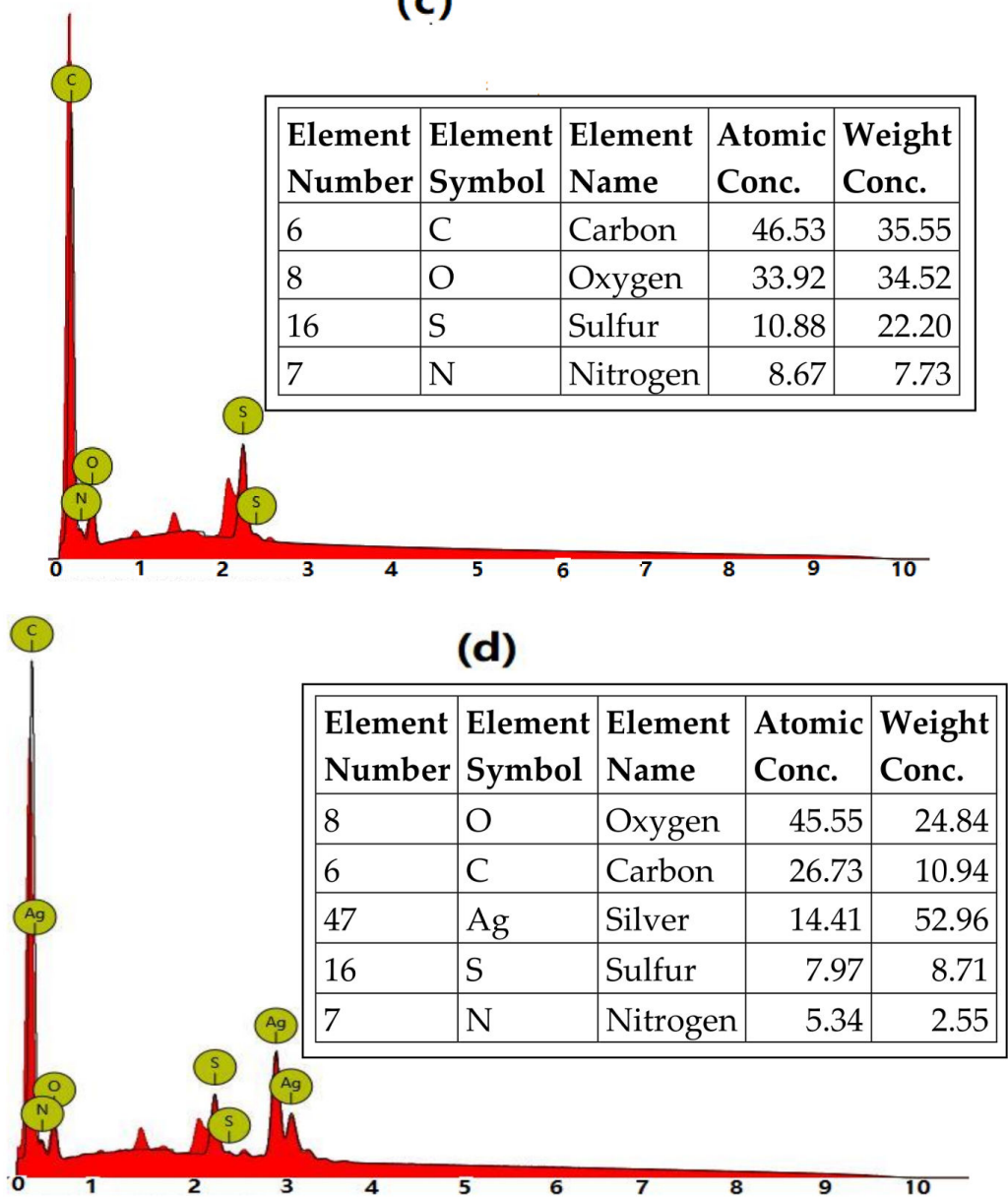

Figure 10. SEM image of BA-PGMA (a) and BA-PGMA-Ag (b), EDS spectrums of BA-PAMA (c) and BA-PGMA-Ag (d). 

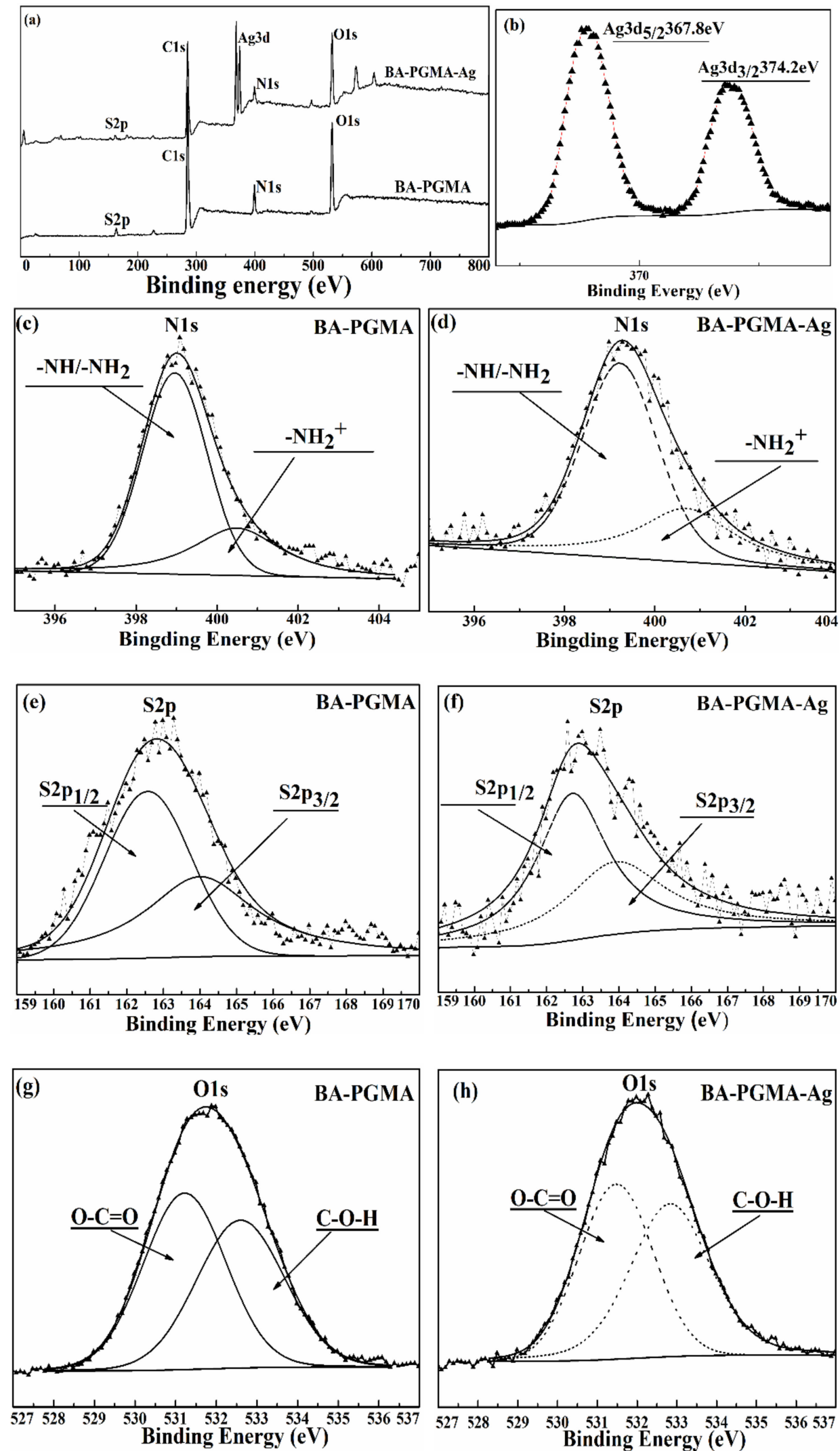

Figure 11. XPS survey scan spectra of BA-PGMA (a) and spectra of BA-PGMA-Ag (b), N1s spectra of BA-PGMA (c) and BA-PGMA-Ag (d), S2p spectra BA-PGMA (e) and BA-PGMA-Ag (f), O1s spectra BA-PGMA (g), and BA-PGMA-Ag (h). 


\subsubsection{Thermodynamic Studies}

In order to study the adsorption thermodynamics of $\mathrm{Ag}(\mathrm{I})$ on BA-PGMA, the effect of temperature on the adsorption of BA-PGMA was studied when the concentration of $\mathrm{Ag}(\mathrm{I})$ was constant. An amount of $10 \mathrm{mg}$ of BA-PGMA was added to a $15 \mathrm{~mL} \mathrm{Ag(I)} \mathrm{solution} \mathrm{and} \mathrm{shaken} \mathrm{at} 250 \mathrm{rpm}$ for $300 \mathrm{~min}$ at $298 \mathrm{~K}, 308 \mathrm{~K}$, and $318 \mathrm{~K}$, respectively. The changes of Gibbs free energy $\left(\Delta G^{\theta}\right)$, standard entropy $\left(\Delta S^{\theta}\right)$, and standard entropy $\left(\Delta H^{\theta}\right)$ were studied. The relationship between them can be expressed by the following formula [61]. Three Ag(I) concentrations $(100 \mathrm{mg} / \mathrm{L}, 200 \mathrm{mg} / \mathrm{L}$ and $300 \mathrm{mg} / \mathrm{L})$ were undertaken.

$$
\begin{gathered}
\Delta G^{\theta}=-R T \ln K_{\mathrm{f}}=\Delta H^{\Theta}-T \cdot \Delta S^{\Theta} \\
\ln K_{\mathrm{f}}=\frac{-\Delta G^{\Theta}}{R T}=\frac{\Delta S^{\Theta}}{R}-\frac{\Delta H^{\Theta}}{R T}
\end{gathered}
$$

where, $k_{\mathrm{f}}$ represent the distribution coefficient and can be calculated by Equation (13), $R$ is the gas constant $(8.314 \mathrm{~J} / \mathrm{mol} / \mathrm{K})$, and $T$ is the temperature in Kelvin $(\mathrm{K})$. According to Equation (16), the data obtained by experiment was linearly fitted as $\ln \left(K_{\mathrm{f}}\right)$ versus $1 / \mathrm{T}\left(K^{-1}\right)$ and the fitting result is shown in Figure 12.

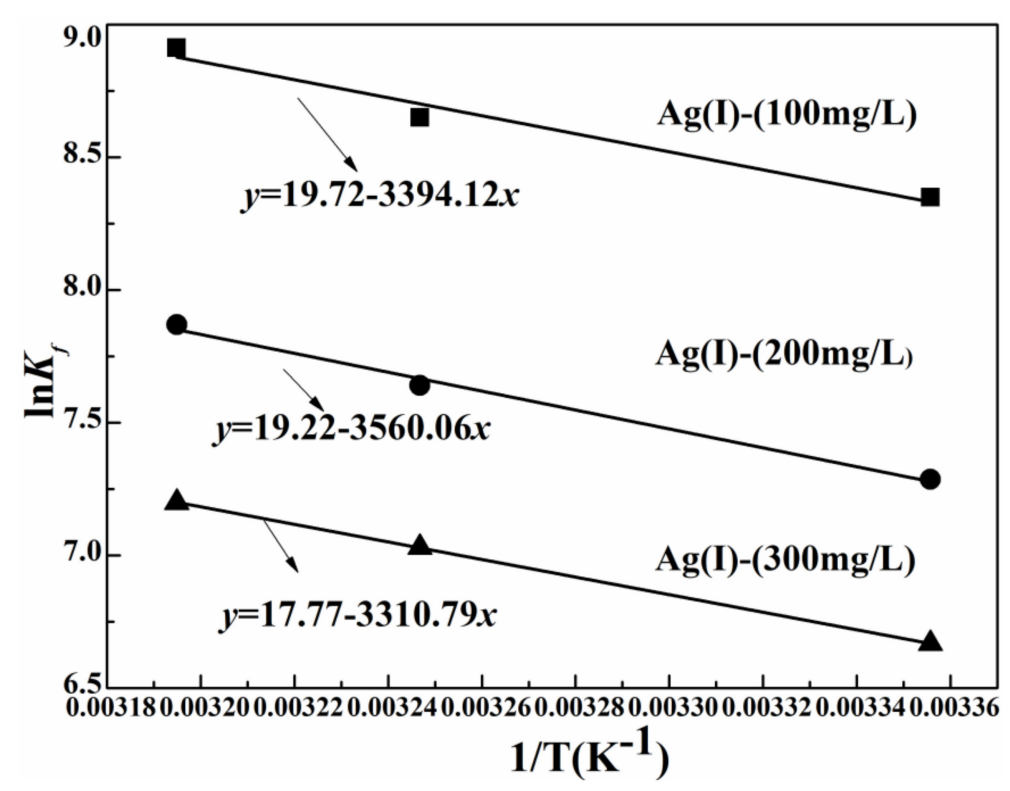

Figure 12. Effect of temperature on the $\mathrm{Ag}(\mathrm{I})$ adsorption capacity.

The standard entropy $\left(\Delta S^{\theta}\right)$ and the standard entropy $\left(\Delta H^{\theta}\right)$ were calculated by the intercept and slope of Figure 12. [62] It can also be seen that the partition coefficient $\left(K_{\mathrm{f}}\right)$ decreased with the reciprocal of temperature. When the concentration was constant, the higher the temperature, the better is the adsorption effect. The relevant parameters are listed in Table 7 . These results indicate that the adsorption process was spontaneous and endothermic in nature, with irregular increase of randomness in the reaction interface of the BA-PGMA/Ag(I) [63]. 
Table 7. Thermodynamic parameters of Ag(I) adsorption onto BA-PGMA.

\begin{tabular}{|c|c|c|c|c|}
\hline Initial Ag(I) Concentration & $T(\mathrm{~K})$ & $\Delta S^{\Theta}\left(\mathrm{J} \cdot \mathrm{K}^{-1} \cdot \mathrm{moL}^{-1}\right)$ & $\Delta \mathrm{H}^{\Theta}\left(\mathrm{kJ} \cdot \mathrm{moL}^{-1}\right)$ & $\Delta G^{\theta}\left(\mathrm{kJ} \cdot \mathrm{moL}^{-1}\right)$ \\
\hline \multirow{3}{*}{$100(\mathrm{mg} / \mathrm{L})$} & $25^{\circ} \mathrm{C}(298 \mathrm{~K})$ & 163.95 & 28.22 & -20.68 \\
\hline & $35^{\circ} \mathrm{C}(303 \mathrm{~K})$ & & & -21.79 \\
\hline & $45^{\circ} \mathrm{C}(313 \mathrm{~K})$ & & - & -23.19 \\
\hline \multirow{3}{*}{$200(\mathrm{mg} / \mathrm{L})$} & $25^{\circ} \mathrm{C}(298 \mathrm{~K})$ & 159.7 & 29.60 & -18.05 \\
\hline & $35^{\circ} \mathrm{C}(303 \mathrm{~K})$ & & & -19.25 \\
\hline & $45^{\circ} \mathrm{C}(313 \mathrm{~K})$ & & - & -20.48 \\
\hline \multirow{3}{*}{$300(\mathrm{mg} / \mathrm{L})$} & $25^{\circ} \mathrm{C}(298 \mathrm{~K})$ & 147.73 & 27.52 & -16.50 \\
\hline & $35^{\circ} \mathrm{C}(303 \mathrm{~K})$ & & & -17.71 \\
\hline & $45^{\circ} \mathrm{C}(313 \mathrm{~K})$ & & - & -18.74 \\
\hline
\end{tabular}

\section{Conclusions}

In this work, a new adsorbent (BA-PGMA) was synthesized by modifying poly(glycidyl methacrylate) to selectively absorb Ag(I) from an aqueous solution. The adsorbent was characterized by FI-TR, SEM, and XPS. The batch experiments showed the optimum $\mathrm{pH}$ was 4.0. The maximum absorption capacity of $\mathrm{Ag}(\mathrm{I})$ at $\mathrm{pH} 4$ and room temperature was $155.05 \mathrm{mg} / \mathrm{g}$. The adsorption equilibrium time was $300 \mathrm{~min}$. The adsorption isotherms are consistent with Langmuir and D-R models. The adsorption kinetics is fitted with a pseudo-secondary model. The BA-PGMA has good selectivity for $\mathrm{Ag}(\mathrm{I})$ for coexisting ions $\left(\mathrm{Cu}^{2+}, \mathrm{Ni}^{2+}, \mathrm{Co}^{2+}, \mathrm{Zn}^{2+}\right)$. At the same time, the adsorption mechanism is of a chelation and electrostatic action. Finally, the adsorbent could be reused to remove silver ions. The adsorption process is exothermic, feasible, and spontaneous. Therefore, it can be concluded that BA-PGMA is a promising adsorbent for recovering $\mathrm{Ag}(\mathrm{I})$ from wastewater.

Author Contributions: S.W. and L.Z. conceived and designed the experiments; J.Z. performed the experiments and wrote the paper; C.W. and B.Z. analyzed the data.

Funding: The support from the National Natural Science Foundation (No. 51,664,037 and U1702252).

Conflicts of Interest: The authors declare no conflict of interest.

\section{References}

1. Farahi, R.H.; Passian, A.; Tetard, L.; Thundat, T. Critical issues in sensor science to aid food and water safety. ACS Nano 2012, 6, 45-48. [CrossRef] [PubMed]

2. Bhatt, I.; Tripathi, B.N. Interaction of engineered nanoparticles with various components of the environment and possible strategies for their risk assessment. Chemosphere 2011, 82, 308-317. [CrossRef] [PubMed]

3. Rao, G.P.; Lu, C.; Su, F. Sorption of divalent metal ions from aqueous solution by carbon nanotubes: A review. Sep. Purif. Technol. 2007, 58, 224-231. [CrossRef]

4. Blaser, S.A.; Scheringer, M.; Macleod, M.; Hungerbühler, K. Estimation of cumulative aquatic exposure and risk due to silver: Contribution of nano-functionalized plastics and textiles. Sci. Total Environ. 2008, 390, 396-409. [CrossRef] [PubMed]

5. Tao, H.C.; Gao, Z.Y.; Ding, H.; Xu, N.; Wu, W.M. Recovery of silver from silver(I)-containing solutions in bioelectrochemical reactors. Bioresour. Technol. 2012, 111, 92-97. [CrossRef] [PubMed]

6. Xiong, Y.; Li, W.; Jing, X.; Wang, Y.; Xing, Z.; Shan, W.; Lou, Z. Selective recovery of Ag(I) coordination anion from simulate nickel electrolyte using corn stalk based adsorbent modified by ammonia-thiosemicarbazide. J. Hazard. Mater. 2016, 301, 277-285. [CrossRef] [PubMed]

7. Shin, K.Y.; Hong, J.Y.; Jang, J. Heavy metal ion adsorption behavior in nitrogen-doped magnetic carbon nanoparticles: Isotherms and kinetic study. J. Hazard. Mater. 2011, 190, 36-44. [CrossRef] [PubMed]

8. Jeon, C. Adsorption of silver ions from industrial wastewater using waste coffee grounds. Korean J. Chem. Eng. 2016, 34, 1-8. [CrossRef]

9. Wajima, T. Synthesis of zeolitic material from green tuff stone cake and its adsorption properties of silver (I) from aqueous solution. Microporous Mesoporous Mater. 2016, 233, 154-162. [CrossRef]

10. Bianchini, A.; Wood, C.M. Mechanism of acute silver toxicity in Daphnia magna. Environ. Toxicol. Chem. 2003, 22, 1361-1367. [CrossRef] 
11. Wawrzkiewicz, M.; Hubicki, Z. Equilibrium and kinetic studies on the sorption of acidic dye by macro porous anion exchange. Chem. Eng. J. 2010, 157, 29-34. [CrossRef]

12. Zhang, L.; Yang, S.; Han, T.; Zhong, L.; Ma, C. Improvement of Ag(I) adsorption onto chitosan/triethanolamine composite sorbent by an ion-imprinted technology. Appl. Surf. Sci. 2012, 263, 696-703. [CrossRef]

13. Tang, B.; Yu, G.; Fang, J.; Shi, T. Recovery of high-purity silver directly from dilute effluents by an emulsion liquid membrane-crystallization process. J. Hazard. Mater. 2010, 177, 377-383. [CrossRef] [PubMed]

14. Virolainen, S.; Tyster, M.; Haapalainen, M.; Sainio, T. Ion exchange recovery of silver from concentrated base metal-chloride solutions. Hydrometallurgy 2015, 152, 100-106. [CrossRef]

15. Das, N. Recovery of precious metals through biosorption-A review. Hydrometallurgy 2010, 103, 180-189. [CrossRef]

16. Ngah, W.S.; Fatinathan, S. Adsorption characterization of $\mathrm{Pb}$ (II) and $\mathrm{Cu}(\mathrm{II})$ ions onto chitosan-tripolyphosphate beads: Kinetic, equilibrium and thermodynamic studies. J. Environ. Manag. 2010, 91, 958-969. [CrossRef] [PubMed]

17. Yu, Z.; Dang, Q.; Liu, C.; Cha, D.; Zhang, H.; Zhu, W.; Zhang, Q.; Fan, B. Preparation and characterization of poly(maleic acid)-grafted cross-linked chitosan microspheres for Cd(II) adsorption. Carbohydr. Polym. 2017, 172, 28-39. [CrossRef] [PubMed]

18. Dang, V.Q.; Lee, J.E.; Kim, J.K.; You, N.K.; Shao, G.N.; Kim, H.T. A gentle method to graft thiol-functional groups onto silica gel for adsorption of silver ions and immobilization of silver nanoparticles. Powder Technol. 2013, 235, 221-227.

19. Liu, P.; Sehaqui, H.; Tingaut, P.; Wichser, A.; Oksman, K.; Mathew, A.P. Cellulose and chitin nanomaterials for capturing silver ions $\left(\mathrm{Ag}^{+}\right)$from water via surface adsorption. Cellulose 2014, 21, 449-461. [CrossRef]

20. Wang, L.; Xing, R.; Liu, S.; Yu, H.; Qin, Y.; Li, K.; Feng, J.; Li, R.; Li, P. Recovery of silver (I) using a thiourea-modified chitosan resin. J. Hazard. Mater. 2010, 180, 577-582. [CrossRef] [PubMed]

21. Madrakian, T.; Afkhami, A.; Zolfigol, M.A.; Solgi, M. Separation, preconcentration and determination of silver ion from water samples using silica gel modified with 2,4,6-trimorpholino-1,3,5-triazin. J. Hazard. Mater. 2006, 128, 67-72. [CrossRef] [PubMed]

22. Duranoğlu, D.; Kaya, İ.G.B.; Beker, U.; Şenkal, B.F. Synthesis and adsorption properties of polymeric and polymer-based hybrid adsorbent for hexavalent chromium removal. Chem. Eng. J. 2012, s181-182, 103-112. [CrossRef]

23. Niu, L.; Deng, S.B.; Yu, G.; Huang, J. Efficient removal of $\mathrm{Cu}(\mathrm{II}), \mathrm{Pb}(\mathrm{II}), \mathrm{Cr}(\mathrm{VI})$ and $\mathrm{As}(\mathrm{V})$ from aqueous solution using an aminated resin prepared by surface-initiated atom transfer radical polymerization. Chem. Eng. J. 2010, 165, 751-757. [CrossRef]

24. Gupta, A.; Jain, R.; Gupta, D.C. Studies on uptake behaviour of $\mathrm{Hg}$ (II) and $\mathrm{Pb}$ (II) by amine modified glycidyl methacrylate-styrene-N, N'-methylene bis-acrylamide terpolymer. React. Funct. Polym. 2015, 93, 22-29. [CrossRef]

25. Dou, X.B.; Chai, M.Y.; Zhu, Y.; Yang, W.T.; Xu, F.J. Aminated Poly(glycidyl methacrylate)s for Constructing Efficient Gene Carriers. ACS Appl. Mater. Interfaces 2013, 5, 32-42. [CrossRef] [PubMed]

26. Liu, C.; Bai, R. Extended study of DETA-functionalized PGMA adsorbent in the selective adsorption behaviors and mechanisms for heavy metal ions of $\mathrm{Cu}, \mathrm{Co}, \mathrm{Ni}, \mathrm{Zn}$, and Cd. J. Colloid Interface Sci. 2010, 350, 282-289. [CrossRef] [PubMed]

27. Wang, L.; Li, F.; Yao, M.; Qiu, T.; Jiang, W.; Fan, L.J. Atom transfer radical polymerization of glycidyl methacrylate followed by amination on the surface of monodispersed highly crosslinked polymer microspheres and the study of cation adsorption. React. Funct. Polym. 2014, 82, 66-71. [CrossRef]

28. Liu, C.; Bai, R.; Hong, L. Diethylenetriamine-grafted poly(glycidyl methacrylate) adsorbent for effective copper ion adsorption. J. Colloid Interface Sci. 2006, 303, 99-108. [CrossRef] [PubMed]

29. Huš, S.; Kolar, M.; Krajnc, P. Separation of heavy metals from water by functionalized glycidyl methacrylate poly (high internal phase emulsions). J. Chromatogr. A 2016, 1437, 168-175. [CrossRef] [PubMed]

30. Sun, X.; Yang, L.; Xing, H.; Zhao, J.; Li, X.; Huang, Y.; Liu, H. High capacity adsorption of Cr(VI) from aqueous solution using polyethylenimine-functionalized poly(glycidyl methacrylate) microspheres. Colloid Surf. A 2014, 457, 160-168. [CrossRef] 
31. Yang, W.; Yun, Z.; Chen, H.; He, X.; Liu, M. Preparation of a novel TETA functionalized magnetic PGMA nano-absorbent by ATRP method and used for highly effective adsorption of $\mathrm{Hg}(\mathrm{II})$. J. Taiwan Inst. Chem. Eng. 2015, 58, 283-289.

32. Liu, W.; Yin, P.; Liu, X.; Dong, X.; Zhang, J.; Xu, Q. Thermodynamics, kinetics, and isotherms studies for gold(III) adsorption using silica functionalized by diethylenetriamine methylene phosphonic acid. Chem. Eng. Res. Des. 2013, 91, 2748-2758. [CrossRef]

33. Hong, S.G. The thermal-oxidative degradation of an epoxy adhesive on metal substrates: XPS and RAIR analyses. Polym. Degrad. Stab. 1995, 48, 211-218. [CrossRef]

34. Zhang, L.; Liu, Y.; Wang, S.; Liu, B.; Peng, J. Selective removal of cationic dyes from aqueous solutions by an activated carbon-based multicarboxyl adsorbent. RSC Adv. 2015, 5, 99618-99626. [CrossRef]

35. Castillo, M.; Criado, A.; Guzmán, R.; Criado, J.J.; Macias, B. Chemistry of dithiocarbamate derivatives of amino acids. Part III. X-ray photoelectron spectroscopy of $\mathrm{Ba}\left(\mathrm{S}_{2} \mathrm{CNHCH}_{2} \mathrm{CO}_{2}\right) \cdot 3 \mathrm{H}_{2} \mathrm{O}$. I.r. and e.s.r. studies of $\alpha$-amino acid-dithiocarbamate complexes of copper(II). Transit. Metal Chem. 1987, 12, 225-229. [CrossRef]

36. Lingamdinne, L.P.; Chang, Y.Y.; Yang, J.K.; Singh, J.; Choi, E.H.; Shiratani, M.; Koduru, J.R.; Attri, P. Biogenic reductive preparation of magnetic inverse spinel iron oxide nanoparticles for the adsorption removal of heavy metals. Chem. Eng. J. 2017, 307, 74-84. [CrossRef]

37. Tanzifi, M.; Hosseini, S.H.; Kiadehi, A.D.; Olazar, M.; Karimipour, K.; Rezaiemehr, R.; Ali, I. Artificial neural network optimization for methyl orange adsorption onto polyaniline nano-adsorbent: Kinetic, isotherm and thermodynamic studies. J. Mol. Liq. 2017, 244, 189-200. [CrossRef]

38. Ho, Y.S.; Mckay, G. Pseudo-second order model for sorption processes. Process Biochem. 1999, 34, 451-465. [CrossRef]

39. Moon, H.; Lee, W.K. Intraparticle diffusion in liquid-phase adsorption of phenols with activated carbon in finite batch adsorber. J. Colloid Interface Sci. 1983, 96, 162-171. [CrossRef]

40. Bhattacharya, A.K.; Naiya, T.K.; Mandal, S.N.; Das, S.K. Adsorption, kinetics and equilibrium studies on removal of $\mathrm{Cr}(\mathrm{VI})$ from aqueous solutions using different low-cost adsorbents. Chem. Eng. J. 2008, 137, 529-541. [CrossRef]

41. Wang, C.; Boithias, L.; Ning, Z.; Han, Y.; Sauvage, S.; Sánchez-Pérez, J.M.; Kuramochi, K. Comparison of Langmuir and Freundlich adsorption equations within the SWAT-K model for assessing potassium environmental losses at basin scale. Agric. Water Manag. 2016, 180, 205-211. [CrossRef]

42. Park, H.S.; Koduru, J.R.; Choo, K.H.; Lee, B. Activated carbons impregnated with iron oxide nanoparticles for enhanced removal of bisphenol A and natural organic matter. J. Hazard. Mater. 2015, 286, 315-324. [CrossRef] [PubMed]

43. Koduru, J.R.; Lingamdinne, L.P.; Singh, J.; Choo, K.H. Effective removal of bisphenol A (BPA) from water using a goethite/activated carbon composite. Process Saf. Environ. 2016, 103, 87-96. [CrossRef]

44. Vijayaraghavan, K.; Padmesh, T.V.N.; Palanivelu, K.; Velan, M. Biosorption of nickel(II) ions onto Sargassum wightii: Application of two-parameter and three-parameter isotherm models. J. Hazard. Mater. 2006, 133, 304-308. [CrossRef] [PubMed]

45. Lou, Z.; Zhao, Z.; Li, Y.; Shan, W.; Xiong, Y.; Fang, D.; Yue, S. Contribution of tertiary amino groups to Re(VII) biosorption on modified corn stalk: Competitiveness and regularity. Bioresour. Technol. 2013, 133, 546-554. [CrossRef] [PubMed]

46. Dąbrowski, A. Adsorption-From theory to practice. Adv. Colloid Interface 2001, 93, 135-224. [CrossRef]

47. Lingamdinne, L.P.; Choi, Y.L.; Kim, I.S.; Yang, J.K.; Koduru, J.R.; Chang, Y.Y. Preparation and characterization of porous reduced graphene oxide based inverse spinel nickel ferrite nanocomposite for adsorption removal of radionuclides. J. Hazard. Mater. 2016, 326, 145-156. [CrossRef] [PubMed]

48. Safavi, A.; Iranpoor, N.; Saghir, N. Directly silica bonded analytical reagents: Synthesis of 2-mercaptobenzothiazole-silica gel and its application as a new sorbent for preconcentration and determination of silver ion using solid-phase extraction method. Sep. Purif. Technol. 2004, 40, 303-308. [CrossRef]

49. Coruh, S.; Senel, G.; Ergun, O.N. A comparison of the properties of natural clinoptilolites and their ion-exchange capacities for silver removal. J. Hazard. Mater. 2010, 180, 486-492. [CrossRef] [PubMed]

50. Liu, P.; Borrell, P.F.; Kokol, V.; Oksman, K.; Mathew, A.P. Nanocelluloses and their phosphorylated derivatives for selective adsorption of $\mathrm{Ag}^{+}, \mathrm{Cu}^{2+}$ and $\mathrm{Fe}^{3+}$ from industrial effluents. J. Hazard. Mater. 2015, 294, 177-185. [CrossRef] [PubMed] 
51. Gülfen, M. Separation and Recovery of Silver(I) Ions from Base Metal Ions by Melamine-formaldehyde-thiourea (MFT) Chelating Resin. Sep. Sci. Technol. 2008, 43, 376-388.

52. Gülfen, M. Separation and Recovery of Silver(I) Ions from Base Metal Ions by Thiourea- or Urea-Formaldehyde Chelating Resin. Sep. Sci. Technol. 2009, 44, 1869-1883.

53. Hou, H.; Yu, D.; Hu, G. Preparation and properties of ion-imprinted hollow particles for the selective adsorption of silver ions. Langmuir 2015, 31, 1376-1384. [CrossRef] [PubMed]

54. Zhang, M.; Helleur, R.; Zhang, Y. Ion-imprinted chitosan gel beads for selective adsorption of $\mathrm{Ag}^{+}$from aqueous solutions. Carbohydr. Polym. 2015, 130, 206-212. [CrossRef] [PubMed]

55. Yurtsever, M.; Şengil, A. Adsorption and desorption behavior of silver ions onto valonia tannin resin. Trans. Nonferrous Metals Soc. China 2012, 22, 2846-2854. [CrossRef]

56. Xiong, C.; Wang, S.; Zhang, L.; Zhou, Y.; Peng, J. Selective recovery of silver from aqueous solutions by poly (glycidyl methacrylate) microsphere modified with trithiocyanuric acid. J. Mol. Liq. 2018, 254, 340-348. [CrossRef]

57. Khan, M.A.; Wallace, W.T.; Islam, S.Z.; Nagpure, S.; Strzalka, J.; Littleton, J.M.; Rankin, S.E. Adsorption and Recovery of Polyphenolic Flavonoids Using $\mathrm{TiO}_{2}$ Functionalized Mesoporous Silica Nanoparticles. ACS Appl. Mater. Interfaces 2017, 9, 32114-32125. [CrossRef] [PubMed]

58. Bogusz, A.; Oleszczuk, P.; Dobrowolski, R. Application of laboratory prepared and commercially available biochars to adsorption of cadmium, copper and zinc ions from water. Bioresour. Technol. 2015, 196, 540-549. [CrossRef] [PubMed]

59. Zhang, L.; Zhang, G.; Wang, S.; Peng, J.; Cui, W. Sulfoethyl functionalized silica nanoparticle as an adsorbent to selectively adsorb silver ions from aqueous solutions. J. Taiwan Inst. Chem. Eng. 2017, 71, 330-337. [CrossRef]

60. Fu, L.; Zhang, L.; Wang, S.; Zhang, G.; Peng, J. Selective recovery of Au(III) from aqueous solutions by nano-silica grafted with 4-(aminomethyl) pyridine. J. Sol-Gel Sci. Technol. 2017, 83, 467-477. [CrossRef]

61. Gavioli, E.; Maier, N.M.; Haupt, K.; Mosbach, K.; Lindner, W. Analyte templating: Enhancing the enantioselectivity of chiral selectors upon incorporation into organic polymer environments. Anal. Chem. 2005, 77, 5009-5018. [CrossRef] [PubMed]

62. Lingamdinne, L.P.; Koduru, J.R.; Roh, H.; Choi, Y.L.; Chang, Y.Y.; Yang, J.K. Adsorption removal of Co (II) from waste-water using graphene oxide. Hydrometallurgy 2016, 165, 90-96. [CrossRef]

63. Pang, S.K.; Yung, K.C. Prerequisites for achieving gold adsorption by multiwalled carbon nanotubes in gold recovery. Chem. Eng. Sci. 2014, 107, 58-65. [CrossRef] 